\title{
Seasonal variations in high time-resolved chemical compositions, sources, and evolution of atmospheric submicron aerosols in the megacity Beijing
}

\author{
Wei Hu${ }^{1, a}$, Min Hu${ }^{1,2}$, Wei-Wei Hu ${ }^{1, b}$, Jing Zheng ${ }^{1}$, Chen Chen ${ }^{1}$, Yusheng Wu ${ }^{1}$, and Song Guo ${ }^{1}$ \\ ${ }^{1}$ State Key Joint Laboratory of Environmental Simulation and Pollution Control, College of Environmental Sciences and \\ Engineering, Peking University, Beijing 100871, China \\ ${ }^{2}$ Beijing Innovation Center for Engineering Science and Advanced Technology, Peking University, Beijing 100871, China \\ anow at: Graduate School of Environmental and Symbiotic Sciences, Prefectural University of Kumamoto, \\ Kumamoto 862-8502, Japan \\ b now at: Cooperative Institute for Research in Environmental Sciences, University of Colorado, Boulder, CO 80309, USA
}

Correspondence to: $\mathrm{Min} \mathrm{Hu}$ (minhu@pku.edu.cn)

Received: 6 February 2017 - Discussion started: 16 February 2017

Revised: 25 July 2017 - Accepted: 26 July 2017 - Published: 25 August 2017

\begin{abstract}
A severe regional haze problem in the megacity Beijing and surrounding areas, caused by fast formation and growth of fine particles, has attracted much attention in recent years. In order to investigate the secondary formation and aging process of urban aerosols, four intensive campaigns were conducted in four seasons between March 2012 and March 2013 at an urban site in Beijing $\left(116.31^{\circ} \mathrm{E}, 37.99^{\circ} \mathrm{N}\right)$. An Aerodyne highresolution time-of-flight aerosol mass spectrometry (HRToF-AMS) was deployed to measure non-refractory chemical components of submicron particulate matter $\left(\mathrm{NR}-\mathrm{PM}_{1}\right)$. The average mass concentrations of $\mathrm{PM}_{1}\left(\mathrm{NR}-\mathrm{PM}_{1}+\right.$ black carbon) were $45.1 \pm 45.8,37.5 \pm 31.0,41.3 \pm 42.7$, and $81.7 \pm 72.4 \mu \mathrm{g} \mathrm{m}^{-3}$ in spring, summer, autumn, and winter, respectively. Organic aerosol (OA) was the most abundant component in $\mathrm{PM}_{1}$, accounting for $31,33,44$, and $36 \%$ seasonally, and secondary inorganic aerosol (SNA, sum of sulfate, nitrate, and ammonium) accounted for 59, 57, 43, and $55 \%$ of $\mathrm{PM}_{1}$ correspondingly. Based on the application of positive matrix factorization (PMF), the sources of OA were obtained, including the primary ones of hydrocarbonlike (HOA), cooking (COA), biomass burning OA (BBOA) and coal combustion OA (CCOA), and secondary component oxygenated OA (OOA). OOA, which can be split into moreoxidized (MO-OOA) and less-oxidized OOA (LO-OOA), accounted for $49,69,47$, and $50 \%$ in four seasons, re-
\end{abstract}

spectively. Totally, the fraction of secondary components (OOA+SNA) contributed about $60-80 \%$ to $\mathrm{PM}_{1}$, suggesting that secondary formation played an important role in the PM pollution in Beijing, and primary sources were also non-negligible. The evolution process of OA in different seasons was investigated with multiple metrics and tools. The average carbon oxidation states and other metrics show that the oxidation state of OA was the highest in summer, probably due to both strong photochemical and aqueousphase oxidations. It was indicated by the good correlations $(r=0.53-0.75, p<0.01)$ between LO-OOA and odd oxygen $\left(\mathrm{O}_{x}=\mathrm{O}_{3}+\mathrm{NO}_{2}\right)$, and between MO-OOA and liquid water content in aerosols. BBOA was resolved in spring and autumn, influenced by agricultural biomass burning (e.g., field preparation burnings, straw burning after the harvest). CCOA was only identified in winter due to domestic heating. These results signified that the comprehensive management for biomass burning and coal combustion emissions is needed. High concentrations of chemical components in $\mathrm{PM}_{1}$ in Beijing, especially in winter or in adverse meteorological conditions, suggest that further strengthening the regional emission control of primary particulate and precursors of secondary species is expected. 


\section{Introduction}

With rapid economic development and urbanization, air pollution has become an increasingly serious issue in China. Severe regional air pollution, mostly characterized by high concentration of fine particulate matter $\left(\mathrm{PM}_{2.5}\right)$, happens frequently. Severe fine particle pollution can lead to visibility deterioration, damage ecosystems and human health, and affect climate change substantially, which has attracted widespread attention. Submicron particulate matter $\left(\mathrm{PM}_{1}\right)$ accounts for a large proportion of both mass and number concentrations in $\mathrm{PM}_{2.5}$. Its physical and chemical properties can be greatly modified by dynamic and chemical conversion processes in the atmosphere (Buseck and Adachi, 2008). A full examination on the properties of chemical compositions, sources, and formation mechanisms of $\mathrm{PM}_{1}$ will improve our abilities to understand, predict, and control its impacts.

Multiple observations have been conducted to investigate the concentrations and chemical compositions of nonrefractory submicron particle $\left(\mathrm{NR}-\mathrm{PM}_{1}\right)$ at diverse sites around the world (Jimenez et al., 2009, and references therein), and also in China (Hu et al., 2016a; Huang et al., 2014; Xu et al., 2014; Sun et al., 2010; and references therein). The $\mathrm{PM}_{1}$ concentration in the megacity Beijing was 2-10 times higher than those in western cities, highlighting the severe situation of particulate pollution. Anthropogenic emissions due to a dense population, as well as the adverse meteorological and geographical conditions, can result in high-PM pollution in Beijing (Hu et al., 2016a).

In urban atmospheres, aerosols can be directly emitted from complicated anthropogenic sources, such as coal and biomass burning, cooking, and traffic-related and industrial emissions, or formed through gas to particle conversion and heterogeneous/aqueous-phase oxidations (Lee and Allen, 2012). Secondary inorganic aerosol (SNA, sum of sulfate, nitrate, and ammonium) is important in $\mathrm{PM}_{1}$ in urban regions (Guo et al., 2014; Huang et al., 2014; Lee, 2015). Organic aerosol (OA) is the most complicated component in fine particles, with a high mass fraction of $20-90 \%$ (Turpin et al., 2000; Carlton et al., 2009). OA is comprised of hundreds of species, but only a small fraction $(\sim 10 \%)$ can be quantified by chemical analysis (Hallquist et al., 2009). A better understanding on OA properties is crucial for identifying the sources of OA.

The Aerodyne aerosol mass spectrometer (AMS) is currently one of the most popular technologies used to characterize the main species in NR-PM 1 and has been applied to many field and laboratory studies (Hallquist et al., 2009). By combining the time series of OA mass spectra (MS) from the AMS with source receptor models, different OA sources can be effectively distinguished. Analyzed with positive matrix factorization (PMF) model, several OA factors have been resolved (Hu et al., 2013; Jimenez et al., 2009; $\mathrm{Ng}$ et al., 2011). For instance, hydrocarbon-like (HOA), cooking (COA), biomass burning (BBOA), and coal combustion
OA (CCOA), etc. are classified into primary organic aerosols (POA). Oxygenated OA (OOA) usually consists of lowvolatility (LV-OOA) and semivolatile OOA (SV-OOA) based on their correlations with sulfate and nitrate, respectively, and inferred volatilities. OOA is also identified as more oxidized (MO-OOA) and less oxidized OOA (LO-OOA) because they show different $\mathrm{O} / \mathrm{C}$ ratios but insignificantly different volatility (Hu et al., 2016a; Setyan et al., 2012). Based on the AMS measurement, the aging process of OA can also be characterized with some metrics, e.g., $\mathrm{C} / \mathrm{H} / \mathrm{O}$ atomic ratios, $\mathrm{OA} / \mathrm{OC}$, carbon oxidation state $\left(\mathrm{OS}_{\mathrm{C}}\right)$, and the abundance of characteristic fragment ions $\left(f_{44}\right.$ and $\left.f_{43}\right)$. These results can help to quantify the contributions of primary emissions and secondary formations and probe into secondary formation mechanisms and the aging process of OA (Ulbrich et al., 2009).

The characteristics and evolution of aerosol pollution are influenced by multiple factors, e.g., meteorological conditions, regional transport, and local sources. Generally, these factors have quite distinct patterns in different seasons; thus the formation, transformation, and removal of pollutants are affected. Some studies on the characteristics of submicron aerosol pollution in Beijing using the AMS were mainly carried out in summer and winter. Characterization of $\mathrm{PM}_{1}$ in summer (e.g., Huang et al., 2010; Sun et al., 2010) and comparisons of $\mathrm{PM}_{1}$ characteristics between summer and winter (e.g., Hu et al., 2016a; Sun et al., 2012; Y. Sun et al., 2013), between the low- and high-humidity atmosphere (e.g., Y. L. Sun et al., 2013), and between the polluted and unpolluted days (e.g., Zhang et al., 2014) have been conducted in Beijing. Yet the study comprehensively characterized the seasonal variations in $\mathrm{PM}_{1}$ under different meteorological conditions and pollutant sources in Beijing is lacking, especially based on high-mass-resolution measurements. Zhang et al. (2013) and Sun et al. (2015) investigated the seasonal variations in $\mathrm{PM}_{1}$ pollution in Beijing based on unit mass resolution (UMR), and there was no elemental information in these studies. High-mass-resolution AMS can obtain elemental information, which can be used to more easily determine the oxidation state of OA and characterize the evolution of secondary OA (SOA). Therefore, to deeply explore the formation and evolution of SOA in urban atmosphere, the researches on $\mathrm{PM}_{1}$ seasonality in Beijing based on field observations applying high-mass-resolution AMS remain very necessary.

In this study, to investigate the seasonal characteristics of $\mathrm{PM}_{1}$, a high-resolution time-of-flight AMS (HR-ToF-AMS) and other online instruments for real-time measurement of gaseous and particulate pollutants were deployed at an urban site in Beijing from 2012 to 2013. First, the seasonal variations in chemical compositions in $\mathrm{PM}_{1}$ were analyzed. Then the seasonal sources of OA were fully explored. Finally, we compared and discussed the evolution process of OA in different seasons. This study is of great significance for further understanding complex air pollution and providing scientific 
support for model simulations of atmospheric aerosols, and also serves as a theoretical basis for fine particulate pollution control.

\section{Experiments}

\subsection{Sampling site and measurements}

During the periods from March 2012 to March 2013, four intensive campaigns were carried out at the PeKing University Urban Atmosphere Environment MonitoRing Station (PKUERS; $39.99^{\circ} \mathrm{N}, 116.31^{\circ} \mathrm{E}$ ), which is located on the roof of a building (approximately $20 \mathrm{~m}$ above ground level) on the campus (Fig. S1 in the Supplement). The details about the observation site were described in several published papers (Wu et al., 2007; Huang et al., 2010). A HR-ToF-AMS (Aerodyne Research Inc., USA) was deployed to measure the mass concentrations and size distributions of submicron nonrefractory species, including OA and inorganic aerosols (sulfate, nitrate, ammonium and chloride). In addition to the HRToF-AMS, multiple high-time-resolution instruments for the measurements of meteorological conditions, and gaseous and particulate pollutants (as listed in Table S1) were also available in these campaigns.

The liquid water content (LWC) in aerosols was roughly estimated with the ISORROPIAII model. The input data included the concentrations of sulfate, nitrate, ammonium, and chloride measured by the AMS, the relative humidity $(\mathrm{RH})$ and temperature of ambient air. The reverse mode and the metastable state of aerosols were selected.

To give an insight into the impacts of regional/longdistance transport on atmospheric aerosols in Beijing, the backward trajectories of air parcels during the observation periods were calculated with the NOAA's HYSPLIT4 trajectory model (http://www.arl.noaa.gov/hysplit.html). A new 3day backward trajectory was traced from the observation site at an altitude of $500 \mathrm{~m}$ above ground level every hour. Cluster analyses of backward trajectories were applied to reveal the major pathways during different campaigns (Sect. S11 in the Supplement).

\subsection{HR-ToF-MS operation and data analysis}

Ambient air was first introduced through a cutoff cyclone of $\mathrm{PM}_{2.5}$ (1.5 $\mathrm{m}$ above the roof) and a copper tube (3/8 in.) at $10 \mathrm{~L} \mathrm{~min}^{-1}$ and was then sampled into the AMS at $0.09 \mathrm{~L} \mathrm{~min}^{-1}$. A Nafion drier was set before the AMS inlet to keep the RH of ambient air sampled into the AMS below $30 \%$. The time resolutions applied in all campaigns were 4 min, with 2 min in $\mathrm{V}$ mode for concentrations and size distributions, and 2 min W mode to obtain the HR-MS data. Ionization efficiency (IE) calibrations were done every few days by sampling monodispersed $400 \mathrm{~nm}$ dried pure $\mathrm{NH}_{4} \mathrm{NO}_{3}$ particles into the AMS. Those particles were aerosolized by an aerosol atomizer (3076, TSI Inc., USA) and selected with a differential mobility analyzer (DMA, model 3081, TSI Inc., USA). IE values measured using the brute-force singleparticle method (BFSP) were used. The ratio of IE to airbeam signal $\left(=\mathrm{IE} / \mathrm{AB}\right.$, where $\mathrm{AB}$ refers to $\mathrm{N}_{2}^{+}$detected by the AMS) of each calibration was applied for converting the instrument signals to actual mass concentrations. The IE / AB calibration values (Fig. S2) within the interval of two calibrations were obtained by linear interpreting IE / AB values before and after. Unless there was an instrument failure (e.g., turbo pump down and filament exchange), the last well-calibrated IE / AB value was applied until the instrument failure time. The size distribution calibration of main species in NR-PM 1 was done in the beginning and ending of all campaigns by selecting pure $\mathrm{NH}_{4} \mathrm{NO}_{3}$ particles (Stokes diameter $50-550 \mathrm{~nm}$ ) with vacuum aerodynamic diameters $\left(d_{\mathrm{va}}\right)$ of $100-900 \mathrm{~nm}$. The detected limits (V mode) of organics, sulfate, nitrate, ammonium, and chloride during all campaigns were shown in Table S2. For the detailed operation and calibration procedures of the HR-ToF-AMS, refer to $\mathrm{Hu}$ et al. (2016a).

For data analysis, we followed the procedures described in $\mathrm{Hu}$ et al. (2016a). Middlebrook et al. (2012) created an algorithm estimating AMS collection efficiencies (CEs) for field data based on the aerosol chemical composition and sampling line RH. The chemical-composition-based CEs (around 0.5) were applied to calculate the mass concentration of chemical compositions in $\mathrm{PM}_{1}$. Good consistencies (Figs. S3-S5) of the results between the AMS and other instruments also prove the reliability of CEs used here. Pieber et al. (2016) found that the $\mathrm{CO}_{2}^{+}$interference related to $\mathrm{NH}_{4} \mathrm{NO}_{3}$ sampling on the vaporizer showed a median of $+3.4 \%$ relative to nitrate, and highly varied between instruments and with operation history (percentiles $P_{10-90}=+0.4$ to $+10.2 \%$ ). The effect of $\mathrm{NH}_{4} \mathrm{NO}_{3}$ on $\mathrm{CO}_{2}^{+}$ion signal was quite limited (about 1-2\%) and not considered here. In this study, the "improved-ambient" correction (Canagaratna et al., 2015) was performed to calculate the elemental ratios of OA. The HR-MS data of OA in four seasons $(\mathrm{m} / \mathrm{z}$ range 12-283 in winter campaign and 12-196 in other campaigns) were analyzed with PMF, respectively, which follows the procedures described in Ulbrich et al. (2009). The optimum solutions were selected following the steps as described in Zhang et al. (2011). The key diagnostic plots of the PMF analyses are shown in Sect. S5 in the Supplement.

\section{Results and discussion}

\subsection{Dynamic variations in $\mathrm{PM}_{1}$ pollution}

\subsubsection{Seasonality of chemical compositions in $\mathbf{P M}_{1}$}

Atmospheric black carbon (BC) particles are mostly in the submicron range because of their formation mechanisms (Bond et al., 2013). The average concentrations of main 
(a)

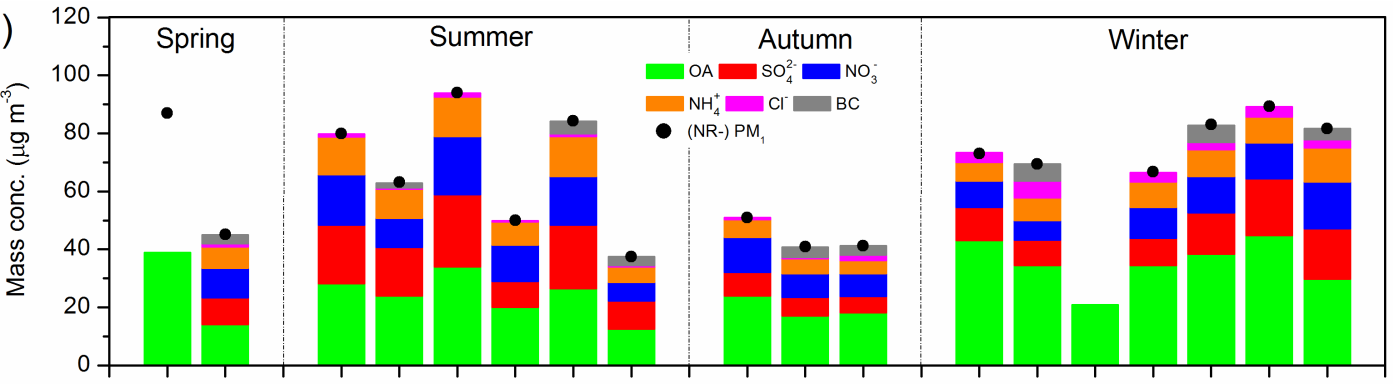

(b)

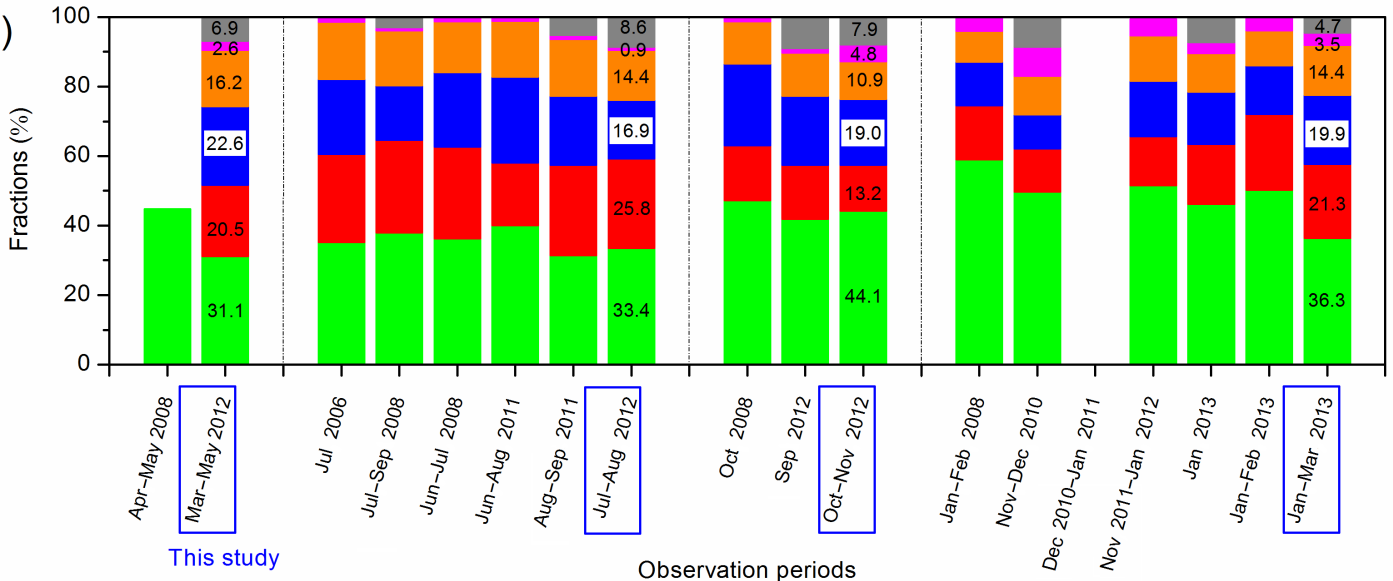

Figure 1. Concentrations (a) and fractions (b) of main chemical components in $\mathrm{PM}_{1}$ during seasonal observations in Beijing in recent years. The data and references are available in Table S3 in the Supplement.

chemical components in $\mathrm{PM}_{1}$ (non-refractory species measured by AMS and BC by Aethalometer or MAAP) and gaseous pollutants, and meteorological conditions are listed in Table 1. The time series of meteorological parameters, including temperature, relative humidity $(\mathrm{RH})$, atmospheric pressure, and wind speed and direction, can be found in Figs. S6-S9.

The average $\mathrm{PM}_{1}$ concentrations showed little difference in spring, summer, and autumn, which were $45.1 \pm 45.8$, $37.5 \pm 31.0$, and $41.3 \pm 42.7 \mu \mathrm{g} \mathrm{m}^{-3}$, respectively. The average $\mathrm{PM}_{1}$ concentration of $81.7 \pm 72.4 \mu \mathrm{g} \mathrm{m}^{-3}$ in winter was the highest among the four seasons. OA was the most important component $(31-44 \%)$ in $\mathrm{PM}_{1}$, similar to previous studies (Fig. 1). In autumn, the contribution of the carbonaceous components $(\mathrm{OA}+\mathrm{BC})$ to $\mathrm{PM}_{1}$ was over $50 \%$. In four seasons, SNA accounted for about $40-60 \%$ in $\mathrm{PM}_{1}$. Secondary inorganics (sulfate and nitrate) correlated well with RH and/or LWC (Table S14), indicating that aqueous-phase reactions in aerosols played an important role in secondary inorganic formation in Beijing. The contribution of photochemical processes to secondary inorganics was likely less than that of aqueous-phase reactions according to the weaker correlations between secondary inorganics and odd oxygen $\left(\mathrm{O}_{x}=\mathrm{O}_{3}+\mathrm{NO}_{2}\right)$. In particular, nitrate did not correlate with $\mathrm{O}_{x}$ in summer (Table S14). Lower temperatures in winter, spring, and autumn favored the partitioning to particulate ni- trate and were partially related to higher concentrations of nitrate in $\mathrm{PM}_{1}$ (Table 1).

Compared with the results obtained over the world, $\mathrm{PM}_{1}$ and the concentrations of major chemical species in Beijing, especially in winter, were 2-10 times higher than those at US and European sites (Hu et al., 2016a). In China, $\mathrm{PM}_{1}$ in urban Beijing in winter was much higher than those results $\left(27-48 \mu \mathrm{g} \mathrm{m}^{-3}\right)$ obtained in the Yangtze River Delta (YRD) and Pearl River Delta (PRD) regions (Gong et al., 2012; He et al., 2011; Huang et al., 2011, 2012, 2013). However, PM $_{1}$ in other seasons was approximate to those obtained at the sites at Changdao Island, and in the YRD and PRD regions in the same seasons (Hu et al., 2013, 2016a, and references therein). These results suggest that Beijing suffered from severe particulate pollution, especially in winter, which should be seriously taken into consideration.

Aerosol pollution in Beijing exhibited distinctive characteristics in four seasons, because of the significantly different meteorological conditions and emission sources of pollutants. Compared with the previous results in Beijing (Fig. 1), $\mathrm{PM}_{1}$ in summer was lower than before, which likely resulted from the more effective washout (Fig. S7) and lower concentrations of gaseous precursors (Table 1 and Table 1 in Sun et al., 2015). In summer, high temperature, strong solar radiation, and high oxidant concentrations generally enhance the secondary aerosol formation from gaseous precursors (such 
Table 1. Seasonal variations in main chemical components in $\mathrm{PM}_{1}$ and gaseous pollutants, and meteorological conditions (temperature, $T$; relative humidity, RH; wind speed, WS; pressure, $P$ ). The data are listed in the form of "average \pm standard deviation". Units of particulate and gaseous pollutants are ppbv and $\mu \mathrm{g} \mathrm{m}^{-3}$, respectively.

\begin{tabular}{|c|c|c|c|c|}
\hline & $\begin{array}{r}\text { Spring } \\
30 \text { Mar-7 May } 2012\end{array}$ & $\begin{array}{r}\text { Summer } \\
29 \text { Jul-29 Aug } 2012\end{array}$ & $\begin{array}{r}\text { Autumn } \\
13 \text { Oct-13 Nov } 2012\end{array}$ & $\begin{array}{r}\text { Winter } \\
23 \text { Jan-2 Mar } 2013\end{array}$ \\
\hline $\mathrm{PM}_{1}$ & $45.1 \pm 45.8$ & $37.5 \pm 31.0$ & $41.3 \pm 42.7$ & $81.7 \pm 72.4$ \\
\hline $\mathrm{OA}$ & $14.0 \pm 11.3$ & $12.5 \pm 7.8$ & $18.2 \pm 17.5$ & $29.7 \pm 25.7$ \\
\hline MO-OOA & $6.8 \pm 6.8$ & $3.3 \pm 2.9$ & $8.6 \pm 8.4$ & $9.8 \pm 8.5$ \\
\hline LO-OOA & & $5.3 \pm 3.6$ & & $5.0 \pm 6.9$ \\
\hline $\mathrm{COA}$ & $2.6 \pm 2.6$ & $2.5 \pm 2.1$ & $5.2 \pm 7.3$ & $4.3 \pm 4.4$ \\
\hline HOA & $2.8 \pm 2.8$ & $1.4 \pm 1.1$ & $2.5 \pm 2.9$ & $5.5 \pm 5.7$ \\
\hline BBOA & $1.8 \pm 1.6$ & & $2.0 \pm 2.7$ & \\
\hline $\mathrm{CCOA}$ & & & & $5.0 \pm 7.2$ \\
\hline $\mathrm{SO}_{4}^{2-}$ & $9.3 \pm 11.5$ & $9.7 \pm 9.9$ & $5.5 \pm 7.3$ & $17.4 \pm 17.9$ \\
\hline $\mathrm{NO}_{3}^{-}$ & $10.2 \pm 13.6$ & $6.4 \pm 8.2$ & $7.9 \pm 10.3$ & $16.2 \pm 15.4$ \\
\hline $\mathrm{NH}_{4}^{+}$ & $7.3 \pm 9.0$ & $5.4 \pm 5.8$ & $4.5 \pm 5.7$ & $11.7 \pm 10.8$ \\
\hline $\mathrm{Cl}^{-}{ }^{4}$ & $1.2 \pm 1.5$ & $0.4 \pm 0.6$ & $2.0 \pm 2.7$ & $2.8 \pm 3.1$ \\
\hline $\mathrm{BC}$ & $3.1 \pm 2.3$ & $3.2 \pm 2.0$ & $3.2 \pm 2.8$ & $3.9 \pm 3.6$ \\
\hline LWC & $17.3 \pm 28.5$ & $18.8 . \pm 24.9$ & $12.8 . \pm 27.3$ & $25.2 . \pm 32.8$ \\
\hline $\mathrm{SO}_{2}$ & $7.4 \pm 7.0$ & $3.1 \pm 3.3$ & $9.2 \pm 8.8$ & $32.0 \pm 21.2$ \\
\hline $\mathrm{CO}$ & $636 \pm 568$ & $671 \pm 317$ & $1229 \pm 1139$ & $2224 \pm 1844$ \\
\hline $\mathrm{NO}$ & $10.5 \pm 21.0$ & $3.5 \pm 6.6$ & $37.5 \pm 44.7$ & $24.4 \pm 30.9$ \\
\hline $\mathrm{NO}_{2}$ & $29.3 \pm 17.7$ & $23.2 \pm 10.4$ & $33.8 \pm 19.4$ & $36.8 \pm 19.3$ \\
\hline $\mathrm{O}_{3}$ & $28.3 \pm 20.6$ & $41.6 \pm 34.7$ & $11.6 \pm 11.5$ & $13.1 \pm 13.0$ \\
\hline$T\left({ }^{\circ} \mathrm{C}\right)$ & $16.8 \pm 4.8$ & $26.8 \pm 4.0$ & $11.2 \pm 4.8$ & $-0.1 \pm 4.0$ \\
\hline $\mathrm{RH}(\%)$ & $33.7 \pm 23.1$ & $61.4 \pm 16.9$ & $43.5 \pm 19.9$ & $37.5 \pm 20.3$ \\
\hline $\mathrm{WS}\left(\mathrm{m} \mathrm{s}^{-1}\right)$ & $2.3 \pm 1.5$ & $1.8 \pm 0.9$ & $1.0 \pm 0.9$ & $2.0 \pm 1.5$ \\
\hline$P(\mathrm{hPa})$ & $1004.2 \pm 5.6$ & $1001.6 \pm 3.4$ & $1012.6 \pm 3.8$ & $1019.2 \pm 5.3$ \\
\hline
\end{tabular}

as $\mathrm{SO}_{2}, \mathrm{NO}_{x}$, and VOCs). As illustrated in Fig. 2, $\mathrm{PM}_{1}$ in summer was mainly in the range of less than $50 \mu \mathrm{g} \mathrm{m}^{-3}$ ( $\sim 80 \%)$, and skew-normally distributed, with the highest frequency $(\sim 45 \%)$ in $15-35 \mu \mathrm{g} \mathrm{m}^{-3}$. The probability distribution of $\mathrm{PM}_{1}$ was similar to the previous results in Beijing in summer (Huang et al., 2010; Sun et al., 2010), but the range of $\mathrm{PM}_{1}$ was narrower. In contrast, $\mathrm{PM}_{1}$ in winter was higher than the previous results in Beijing before 2013, and equivalent to those in close periods from January to February 2013 (Fig. 1; Zhang et al., 2014; Sun et al., 2014). The heaviest particulate pollution in winter was the co-effect of the large amount of particles emitted from primary sources, prolonged control of weak weather system (i.e., low mixed layer and static air), and the rapid generation and accumulation of secondary particles from gaseous precursors $(\mathrm{Hu}$ et al., 2016a; Y. Sun et al., 2013).

In spring, autumn, and winter, the passage of strong cold air parcels transported from Siberia and Mongolia through Beijing (Sect. S11) was usually accompanied by strong winds, thus atmospheric relative humidity decreased, pressure increased, which was conductive to the dispersal of pollutants (Figs. S6, S8, and S9). The heavy pollution processes were usually ended by the passages, demonstrating periodic cycles of aerosol pollution (Guo et al., 2014; Wu et al.,
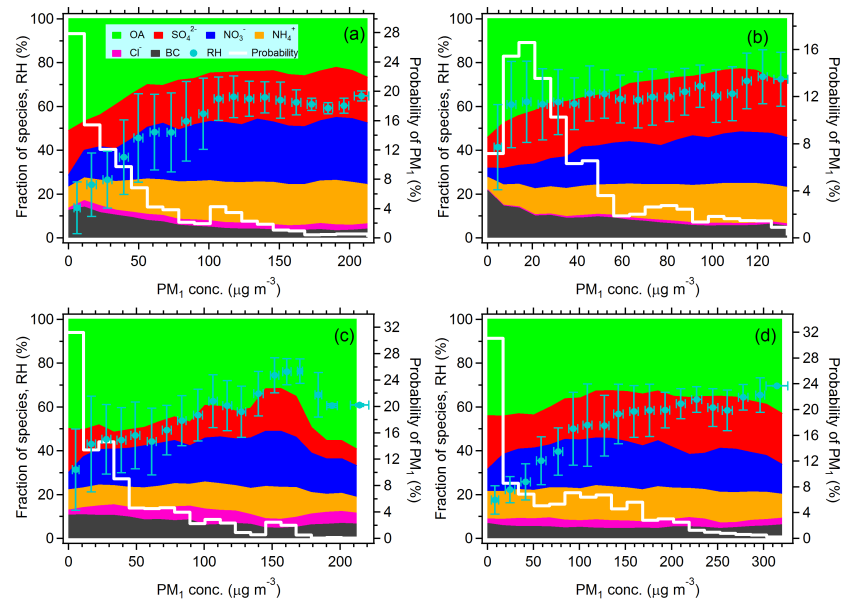

Figure 2. Fractions of main chemical compositions in submicron aerosols at different $\mathrm{PM}_{1}$ levels, and the probability density of $\mathrm{PM}_{1}$ (white curves) during the spring (a), summer (b), autumn (c), and winter (d) observations. The average $\mathrm{RH}$ values in each segment are illustrated and the error bars in the $x$ and $y$ axis were the standard deviations of $\mathrm{PM}_{1}$ and $\mathrm{RH}$, respectively. 
2009). In spring and autumn, the biomass burning emissions in North China occurred often due to agricultural activities and traditional activities around Tomb-Sweeping Day (early April). Dense fire points were frequently observed by satellites (https://firms.modaps.eosdis.nasa.gov/firemap) in Beijing and surrounding areas (Figs. S10-S11). For instance, during 7-8 and 26-28 April, 18-20 and 23-27 October, and 6-11 November 2012, the concentrations of OA and other pollutants increased substantially (Figs. S6 and S8). Higher nitrate concentrations in spring and autumn, likely caused by the secondary conversion of gaseous nitrogen oxides emitted from biomass burning (Fabian et al., 2005). The probability distributions of $\mathrm{PM}_{1}$ in spring, autumn and winter were quite different from that in summer (Fig. 2), because the scavenging effect of strong wind was apparent due to the intrusion of long-range-transported air parcels. $\mathrm{PM}_{1}$ mainly concentrated in the range of low levels $\left(<20 \mu \mathrm{g} \mathrm{m}^{-3}\right)$, with frequencies of $40-60 \%$. However, $\mathrm{PM}_{1}$ ranged much more broadly, with the highest concentrations of over 200 or $300 \mu \mathrm{g} \mathrm{m}^{-3}$, resulting from accumulated pollutants under strong primary emissions coupled with extremely unfavorable meteorological conditions, e.g., long-lasting stagnant weather, high humidity, and temperature inversion.

\subsubsection{Contributions of chemical compositions to the $\mathrm{PM}_{1}$ increase}

The contributions of chemical components in atmospheric aerosols at different concentration levels can help better understand the origins of chemical components. The proportions of chemical compositions as a function of $\mathrm{PM}_{1}$ are shown in Fig. 2.

In all seasons, at low $\mathrm{PM}_{1}$, the contribution of carbonaceous components $(\mathrm{OA}+\mathrm{BC})$ was dominant, accounting for $50-80 \%$ of $\mathrm{PM}_{1}$. With the increase in $\mathrm{PM}_{1}$, the proportions of SNA in $\mathrm{PM}_{1}$ increased gradually, indicating that the enhancement of SNA primarily contributed to the increase in $\mathrm{PM}_{1}$, consistent with previous studies (Huang et al., 2010; Sun et al., 2010, 2012). The proportions of nitrate increased significantly and the nitrate concentration increased rapidly under higher RH (Figs. 2 and S6-S9). Nitrate showed good correlations with RH (Pearson correlation coefficients $r=0.34-0.79, p<0.01$ ) and the LWC in aerosols $(r=0.82-0.87, p<0.01)$. These results indicate that the aqueous-phase reactions in wet aerosols and/or clouds could substantially contribute to nitrate formation. It is worth noting that when $\mathrm{PM}_{1}$ higher than $150 \mu \mathrm{g} \mathrm{m}^{-3}$, carbonaceous aerosols dominated $\mathrm{PM}_{1}$ again in autumn, mainly resulting from large amounts of primary emissions. The proportions of chemical components in $\mathrm{PM}_{1}$ varied less significantly in winter, reflecting the characteristics of regional pollution over the North China under the control of static weather system.
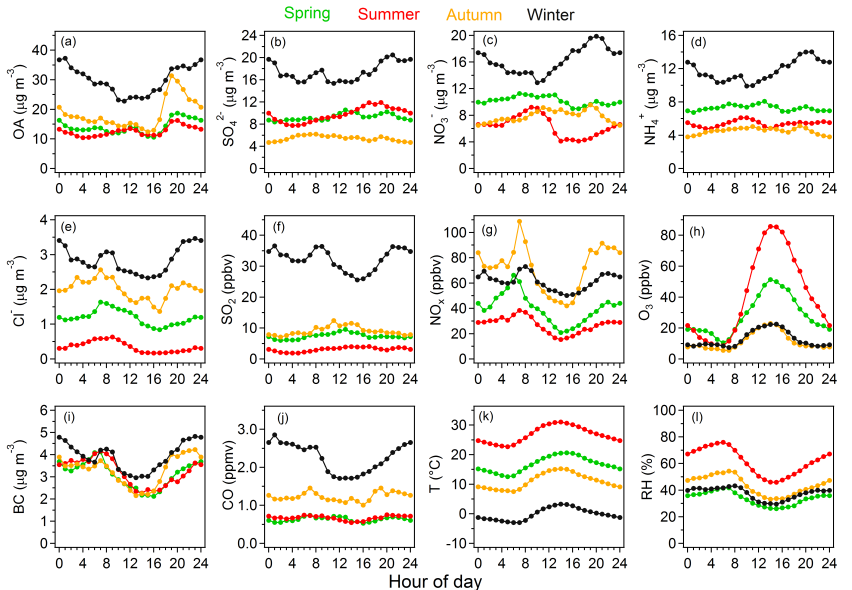

Figure 3. Diurnal patterns of chemical species of $\mathrm{PM}_{1}$, gaseous pollutants, temperature $(T)$, and relative humidity $(\mathrm{RH})$ during seasonal observations. The ranges of diurnal variations for each season are shown in Figs. S12-S15.

\subsubsection{Diurnal patterns of chemical compositions in $\mathbf{P M}_{1}$}

Affected by different meteorological conditions, e.g., solar radiation, temperature, $\mathrm{RH}$, boundary layer, and mountainvalley breezes (Fig. S7), as well as different emission sources, the chemical compositions in $\mathrm{PM}_{1}$ showed distinct diurnal patterns in four seasons. The diurnal patterns of gaseous and particulate pollutants during the seasonal observations are shown in Fig. 3.

Diurnal patterns of OA were similar in spring, summer, and autumn. OA showed two obvious peaks around noon and in the evening. Similar peaks were also observed in winter, but these were not as strong as in the other seasons. These two peaks corresponding to meal time were mainly caused by cooking emissions, which will be discussed later in Sect. 3.2.1. The peak concentration of OA in the evening in autumn was about 2 times higher than in spring and summer, consistent with the results in October-November 2011 (Sun et al., 2015), possibly because of the more intensive cooking activities. In autumn, charcoal grilling, or barbecuing, has become one of the most popular outdoor recreational activities in urban Beijing and surrounding areas, due to more moderate and pleasant weather conditions than in other seasons (Table 1). In winter study, OA increased at night due to extra primary emissions, e.g., coal combustion and biomass burning.

Compared with OA diurnal patterns, flatter diurnal cycles of sulfate were observed in four seasons, identifying the regional characteristics of sulfate formation (Sun et al., 2015). In spring, sulfate showed small peaks around 13:00 and 20:00. In the daytime, both active photochemical production and more favorable dispersion conditions due to a higher planetary boundary layer (PBL), possibly caused such a di- 
urnal pattern of sulfate. In summer, sulfate enhanced gradually from morning to evening and peaked in the evening only, indicating that the photochemical production of sulfate might be significant. Guo et al. (2010) reported that in addition to the gas-phase processes, the formation of sulfate was mainly attributed to aqueous-phase reactions in clouds and/or wet aerosols (70-80\%) in the summer of Beijing. The aqueous-phase formation of sulfate in summer should also be more intense than in spring and autumn due to high temperature and high humidity (Fig. 3k-1). In winter, sulfate showed two peaks in the morning (06:00-10:00) and evening (around 20:00), which was likely influenced by the secondary formation of primarily emitted $\mathrm{SO}_{2}$ (Fig. 3f). The lower sulfate concentration in the daytime was quite related to the dilution effect of the planetary boundary layer (PBL). The PBL height decreases at night, and the atmospheric stability increases, thus the pollutants are difficult to spread (Hu et al., 2016a).

Nitrate showed distinct diurnal patterns in four seasons. Heterogeneous/aqueous-phase reactions and gas-to-particle condensation processes are the main pathways to form finemode nitrate (Guo et al., 2010). In summer, nitrate exhibited an obvious diurnal pattern with the concentrations gradually decreasing in the daytime, indicating that $\mathrm{NH}_{4} \mathrm{NO}_{3}$ evaporated due to high temperatures (Fig. $3 \mathrm{k}$ ) and overcame the photochemical production of nitrate. The elevated PBL also plays a role in reducing the concentration of nitrate in the daytime (Sun et al., 2015). In winter, nitrate increased gradually during 09:00-20:00, which did not appear in other seasons, suggesting that in addition to photochemical processes in the daytime, the partitioning of $\mathrm{NH}_{4} \mathrm{NO}_{3}$ into particulate nitrate was more significant due to low temperatures $\left(<5^{\circ} \mathrm{C}\right.$; Fig. $\left.3 \mathrm{k}\right)$. Similar diurnal patterns in summer and winter have been observed in previous studies (Sun et al., 2015). In autumn, nitrate increased in the morning and then later in the evening, primarily driven by the photochemical production. The diurnal variation in nitrate in spring was insignificant. Because ammonium mainly existed in the forms of $\left(\mathrm{NH}_{4}\right)_{2} \mathrm{SO}_{4}$ and $\mathrm{NH}_{4} \mathrm{NO}_{3}$, its diurnal patterns generally exhibited a combined effect of sulfate and nitrate formation mechanisms. In summer, the diurnal variation in ammonium correlated better $(r=0.55, p<0.01)$ with that of nitrate than sulfate $(r=0.19, p>0.05)$. In other seasons, the diurnal variations in ammonium showed good correlations with those of both sulfate and nitrate $(r=0.50-0.98, p<0.01$ or 0.05).

Chloride showed higher concentrations at night, with a peak in the morning, and then deceased in the daytime. Such a diurnal pattern was possibly caused by high primary emissions of chloride at night. It was also driven by the diurnal patterns of both temperatures and the PBL height, and controlled by the temperature-dependent gas-particle partitioning (Hu et al., 2016a; Sun et al., 2015). Chloride usually presents at semivolatile state in the form of ammonium chloride in urban areas (Zhang et al., 2005); therefore the diur- nal cycles of chloride and temperature trend oppositely. In winter, chloride was higher at night because of coal combustion and biomass burning emissions. Hu et al. (2016a) estimated that in winter over $50 \%$ of chloride in $\mathrm{PM}_{1}$ existed as $\mathrm{NH}_{4} \mathrm{Cl}$, and part of chloride existed as $\mathrm{KCl}$ and $\mathrm{NaCl}$. $\mathrm{BC}$ was mainly affected by the diurnal variation in the $\mathrm{PBL}$ height. BC showed a marked rise at night (around 21:0000:00) and a small morning peak (07:00-08:00). Nocturnal heavy-duty vehicular exhausts (Lin et al., 2009; Hu et al., 2012), coal combustion, and biomass burning emissions in the urban atmosphere also contributed to the high concentration of $\mathrm{BC}$ at night. The morning peak of $\mathrm{BC}$ was consistent with that of $\mathrm{NO}_{x}$, probably due to vehicular emissions during rush hour.

\subsubsection{Size distributions of chemical compositions in $\mathbf{P M}_{1}$}

The mass size distributions of chemical compositions in $\mathrm{PM}_{1}$ during seasonal campaigns are shown in Fig. 4. The size distributions of SNA concentrated in accumulation mode, peaking at about $600-800 \mathrm{~nm}\left(d_{\mathrm{va}}\right)$, indicating the internally mixed states of submicron aerosols. The mode diameters of SNA in Beijing were higher than those $(500-600 \mathrm{~nm})$ in Hong Kong in four seasons (Li et al., 2015). The mode size $(700 \mathrm{~nm})$ of sulfate was smaller than that $(790 \mathrm{~nm})$ of nitrate in autumn. In contrast, the mode size of sulfate $(760 \mathrm{~nm})$ was larger than that $(700 \mathrm{~nm})$ of nitrate in winter. The size distribution of ammonium was more consistent with that of nitrate than sulfate in winter. More nitrate likely existed in the form of $\mathrm{NH}_{4} \mathrm{NO}_{3}$, formed by the reaction of gaseous $\mathrm{HNO}_{3}$ and $\mathrm{NH}_{3}$ condensed on atmospheric particles (Weimer et al., 2006).

During the winter, the peak size of OA was close to those of SNA, while in other seasons it was smaller than those of SNA, indicating a more aged state of OA in winter. The mass size distributions of chemical components in winter were also similar to those in the heavy-pollution episodes in other seasons, consistent with the severity of aerosol pollution in winter. In spring, summer, and autumn, the size distributions of OA were wider than those of SNA. The OA concentrations were much higher than those of SNA in the range of small size $(100-500 \mathrm{~nm})$, similar to the results in other urban areas (Weimer et al., 2006; Aiken et al., 2009), probably caused by the contribution of POA (Huang et al., 2010; Hu et al., 2013). In particular, influenced by primary emissions, the concentration of OA at peak size was much higher than those of other species in autumn. During the spring, summer and autumn, the proportions of OA decreased, while those of SNA increased rapidly with the increase in particle size $(>200 \mathrm{~nm})$. SNA contributed predominantly to the enhancement of $\mathrm{PM}_{1}$, in accordance with that mentioned in Sect. 3.1.2. Different OA sources played different roles with the increase in particle size in winter, and the proportion of OA (about $40 \%$ ) varied slightly. However, the proportions of 

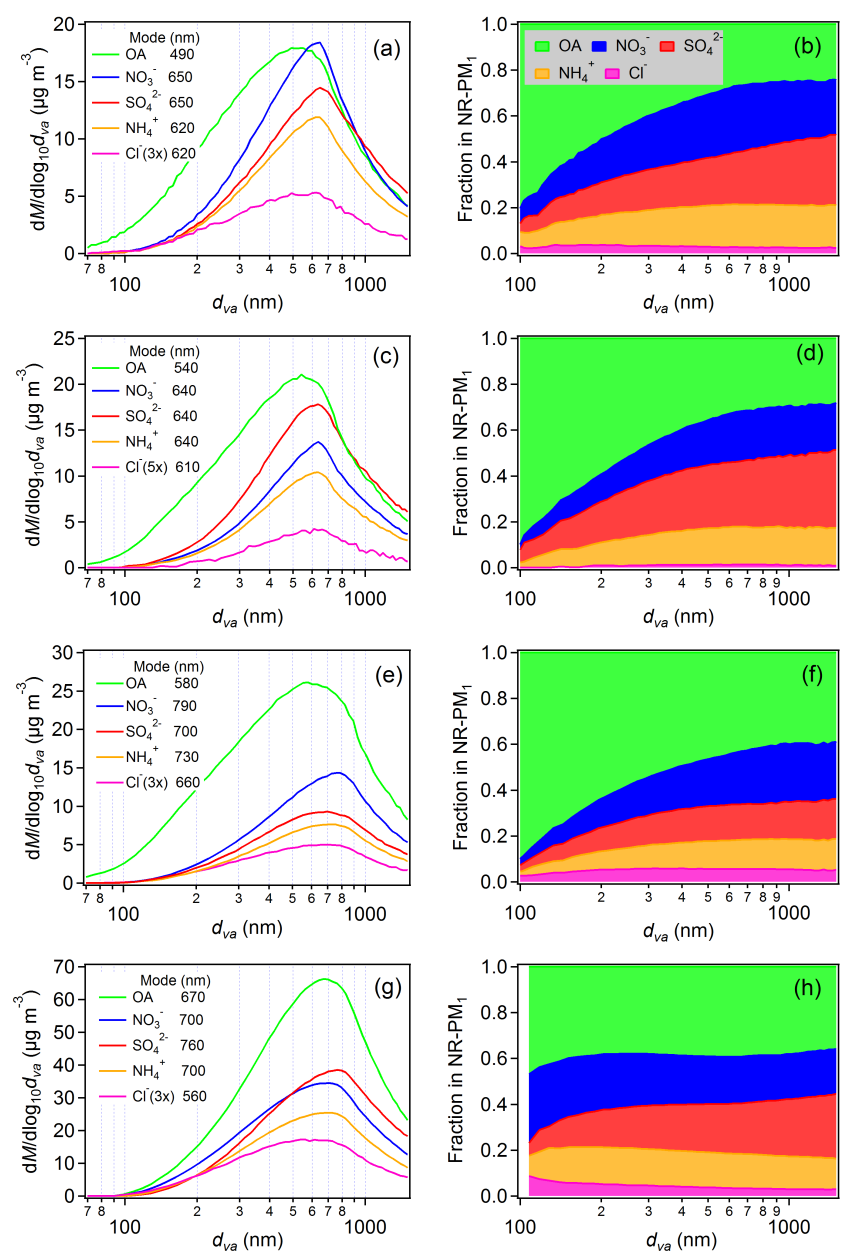

Figure 4. Mass size distributions of chemical compositions in NR$\mathrm{PM}_{1}$ during the spring $(\mathbf{a}, \mathbf{b})$, summer $(\mathbf{c}, \mathbf{d})$, autumn $(\mathbf{e}, \mathbf{f})$, and winter $(\mathbf{g}, \mathbf{h})$ observations.

sulfate rose with the increase in size, implying the significant contribution of regionally transported sulfate.

\subsection{Investigating OA sources with PMF}

The sources of OA in four seasons were resolved by combining high-resolution OA mass spectra and PMF model respectively. The resolved fractions of OA during seasonal observations are shown in Fig. 5. The mass spectra and time series of OA components and some external tracers in each season are shown in Figs. S28-S31 and S32-S35, respectively.

In spring and autumn, four OA components, i.e., OOA, COA, BBOA, and HOA, were identified. The fractions of POA (sum of HOA, COA, and BBOA) were slightly higher than those of OOA because primary emissions (e.g., biomass burning) strongly influenced Beijing and surrounding areas. In autumn, the fraction of POA was close to that in the autumn of 2008 (Fig. 5b). OA was comprised of MOOOA, LO-OOA, COA, and HOA in summer. OOA (MO-
OOA+LO-OOA) dominated OA (69\%), signifying the predominant contribution of SOA formation. Consistent with previous results, the contribution of SOA to OA is about 60 $70 \%$ of $\mathrm{OA}$ in the summer in Beijing, which has been quite stable in recent years (Fig. 5; Guo et al., 2012, 2013). In winter, five components (MO-OOA, LO-OOA, COA, HOA, and CCOA) were resolved. Secondary formations and primary emissions (e.g., biomass burning and fossil fuel combustion) contributed to OA equivalently. The fraction of SOA in OA in winter $(50 \%)$ was much higher than those fractions $(20$ $30 \%$ ) in previous studies, and comparable to the results in the same winter in Beijing (Fig. 5b and Table S8), which was related to effective SOA formation under the stable meteorological conditions during long-lasting severe haze episodes.

The comparison of seasonal variations in $\mathrm{OA}$ in $\mathrm{PM}_{1}$ between this study and studies carried out at other sites is shown in Fig. 5c. The fractions of SOA during all seasons in Beijing were higher than or comparable to those at Mt. Tai (1534 m a.s.1.), North China (Zhang et al., 2014). Both in Beijing and at Mt. Tai, the fractions of SOA were higher in summer than in other seasons. The contribution of SOA to $\mathrm{OA}$ in Beijing was much lower than those in less-polluted atmospheres in Hong Kong ( $\mathrm{Li}$ et al., 2015) and the southeastern USA (Budisulistiorini et al., 2016). The fraction of SOA in OA was as high as $80-86 \%$ in Hong Kong in four seasons. At a downtown site in Atlanta, SOA accounted for over $80 \%$ in spring and summer, and 65 and $56 \%$ in autumn and winter. At a rural/forested site Look Rock, Great Smoky Mountains, no POA sources were resolved except for BBOA in winter. Different from the two sites in southeastern USA, there was no isoprene-epoxydiols-derived SOA (IEPOX-SOA) and a biogenically influenced factor characterized by distinct $m / z, 91$ resolved in urban Beijing. No IEPOX-SOA factor (i.e., below the PMF detection limit of $\sim 5 \%$ of OA) was found in Beijing because the formation of IEPOX-SOA under IEPOX-poor and polluted urban environments is quite limited (Hu et al., 2015).

Overall, the proportions of OOA in OA in this study were comparable to the average (58\%) obtained at other urban sites around the world (Zhang et al., 2011). In total, secondary species (SNA+SOA) accounted for 74, 80, 64 and $73 \%$ of the total $\mathrm{PM}_{1}$, respectively. The serious secondary pollution stresses the importance of control measures targeting the emission reduction of gaseous precursors, e.g., $\mathrm{NO}_{x}$, $\mathrm{SO}_{2}$, and VOCs (Guo et al., 2014; Pye et al., 2013).

\subsubsection{Primary OA sources}

\section{COA}

COA refers to OA emitted from cooking activities (Allan et al., 2010). The knowledge on the transformation of COA in the atmosphere is limited (Dall'Osto et al., 2015). The reductive alkyl fragment ions are abundant in the MS of COA (Figs. S28-S31). The abundance of fragments $m / z 55$ and 
(a)

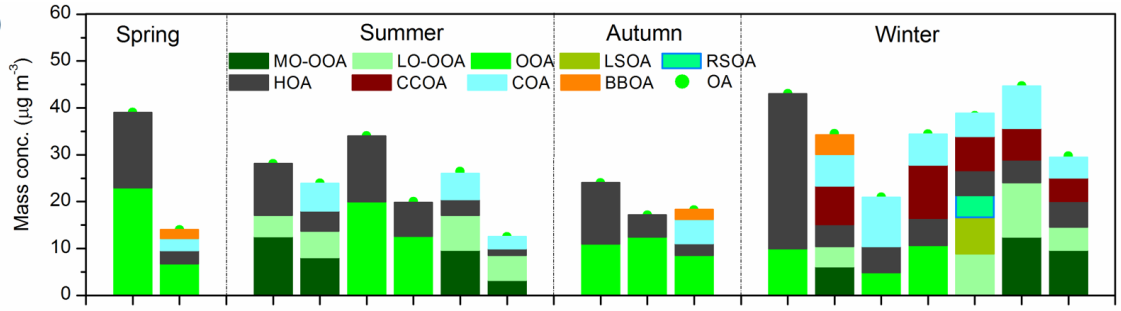

(b)
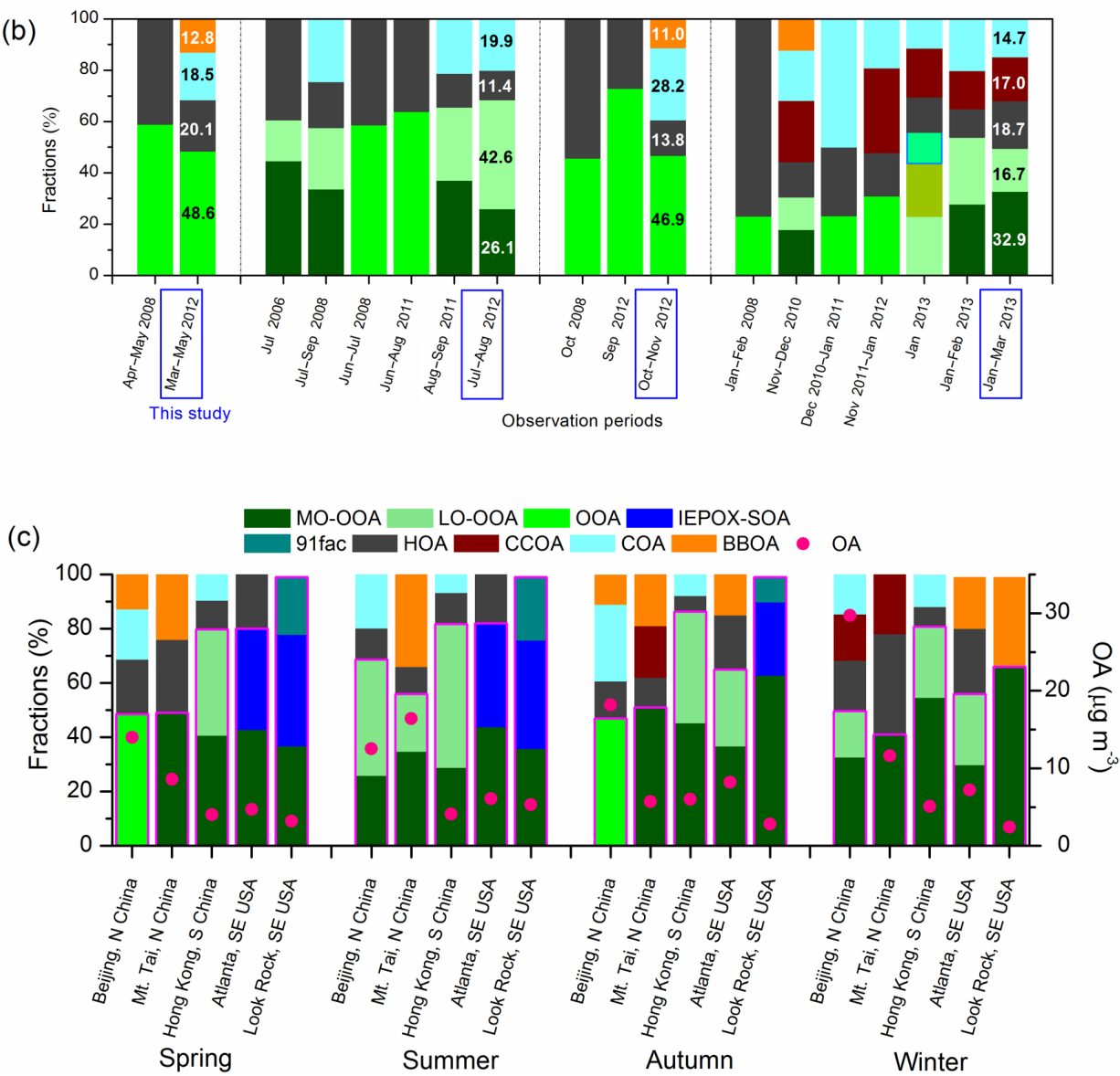

Figure 5. Resolved components of OA during seasonal observations in Beijing (a and $\mathbf{b}$; data and references are listed in Table S8 in the Supplement) and at other sites (c) in Mt. Tai (Zhang et al., 2014), Hong Kong (Li et al., 2015) and the southeastern USA (Budisulistiorini et al., 2016) in recent years. LSOA, local SOA; RSOA, regional SOA; 91fac, a biogenically influenced factor characterized by distinct $m / z$ 91. MO-OOA and LO-OOA are identified as LV-OOA and SV-OOA, respectively, except for during August-September 2011 and NovemberDecember 2010 (Hu et al., 2016a), and in this study.

$m / z 57\left(f_{55}\right.$ and $f_{57}$, mass fractions of $m / z 55$ and $\left.m / z 57\right)$ in the MS of COA were about 7-10 and 3-4\%, respectively. Higher $f_{55}$ and $f_{57}$ are the most remarkable characteristic in the MS of identified COA factors, which are crucial to identify COA and HOA (Mohr et al., 2012). In this study, $f_{55}$ in COA factors was significantly higher than in corresponding HOA factors, and $f_{57}$ in COA factors was comparable to $f_{57}$ in corresponding HOA factors (Figs. S28-S31). The oxidation state of COA was low, with low $\mathrm{O} / \mathrm{C}(0.13-0.23)$ and OA / OC (1.33-1.46) ratios in this study.
As the edible oil is rich in oleic and linoleic acids (Dyer et al., 2008), the fragments $m / z 55$ and $m / z 57$ are not only contributed by the reductive alkyl fragments $\mathrm{C}_{4} \mathrm{H}_{7}^{+}$and $\mathrm{C}_{4} \mathrm{H}_{9}^{+}$ but also by oxygenated fragments $\mathrm{C}_{3} \mathrm{H}_{3} \mathrm{O}^{+}$and $\mathrm{C}_{3} \mathrm{H}_{5} \mathrm{O}^{+}$. The mass fractions of the later ones were about one-third of those of the reductive alkyl fragments with the same $m / z$. The ratios of oxygenated and reductive fragments $m / z .55$ and $m / z 57$ are used to identify the sources of OA. The ratio of $\mathrm{C}_{3} \mathrm{H}_{3} \mathrm{O}^{+}$to $\mathrm{C}_{3} \mathrm{H}_{5} \mathrm{O}^{+}$in $\mathrm{COA}$ is about 2 , while in $\mathrm{HOA}$ it is about 1 ; the ratio of $\mathrm{C}_{4} \mathrm{H}_{7}^{+}$and $\mathrm{C}_{4} \mathrm{H}_{9}^{+}$in $\mathrm{COA}$ is about 2.5 and that in HOA is approximately 1 (Mohr et al., 2012). In 
this study, the ratios of $\mathrm{C}_{3} \mathrm{H}_{3} \mathrm{O}^{+}$to $\mathrm{C}_{3} \mathrm{H}_{5} \mathrm{O}^{+}$in $\mathrm{COA}$ were 2.7, 3.4, 3.8, and 2.4, and in HOA were 4.1, 0.6, 0.0, and 1.3; the ratios of $\mathrm{C}_{4} \mathrm{H}_{7}^{+}$and $\mathrm{C}_{4} \mathrm{H}_{9}^{+}$in $\mathrm{COA}$ and $\mathrm{HOA}$ were 2.3 , $1.8,2.3$, and 2.4 , and $1.4,1.6,1.1$, and 1.1 , respectively.

The reasonability of resolved COA factors was investigated through their concentrations, diurnal patterns, correlations of COA with external tracers, and the uncentered correlations (UC) of MS. The COA concentrations could be simply estimated with the formula provided by Mohr et al. (2012) based on the fragments $m / z 55, m / z 57$ and $m / z$ 44. The estimated COA concentrations were 4.7, 4.4, 6.5 , and $5.3 \mu \mathrm{g} \mathrm{m}^{-3}$ in four seasons, accounting for $33,35,35$ and $18 \%$ of OA, respectively. Compared with the concentrations (2.6, 2.5, 5.2 and $\left.4.3 \mu \mathrm{g} \mathrm{m}^{-3}\right)$ and proportions (19, 20, 28, and $15 \%$ ) based on the AMS-PMF analysis (Fig. 5), the results were overestimated, especially in summer, which is likely related to the applicability of experience parameters in different regions and seasons. The COA factors showed apparent diurnal patterns during seasonal observations, which is a key feature in identifying COA (see Sect. 3.2.3).

COA correlated well with some gaseous and other particulate pollutants, e.g., $\mathrm{NO}_{x}$ and BC (Tables S9-S12). Dall'Osto et al. (2015) considered that the COA factors at a rural site contained more sources other than cooking emissions, based on the good correlations between COA with $\mathrm{HOA}, \mathrm{BC}, \mathrm{NO}_{x}$, nitrate, etc. The UC coefficients (Ulbrich et al., 2009) between the MS of resolved COA factors in this study and the average MS of COA in previous studies (Lanz et al., 2008; Mohr et al., 2009; Huang et al., 2010; He et al., 2010) were calculated. The UC coefficients were in the range of 0.910 0.990 (Table S13), confirming the good similarity and rationality of the resolved COA factors.

In previous studies, it was reported that $\mathrm{COA}$ accounted for $14-25 \%$ ( $\sim 20 \%$ on average) of the total OA in summer and winter in Beijing, with an average concentration $\left(\sim 6 \mu \mathrm{g} \mathrm{m}^{-3}\right)$, which is a relatively stable component of OA (Hu et al., 2016a; Wang et al., 2009). In this study, the concentrations and proportions of COA in OA during seasonal observations were in the range of $2.5-5.2 \mu \mathrm{g} \mathrm{m}^{-3}$ and $15-$ $28 \%$, respectively, comparable to previous results. The highest concentration and proportion of COA in autumn were likely caused by strong emissions from charcoal-grilling or barbecue activities, which are popular in Beijing and surrounding areas in autumn as mentioned above. Fewer cooking activities during and around the Chinese New Year holiday (7-19 February) and the lower evaporation rates of cooking oils (Ndiaye et al., 2005) led to the lower concentration and proportion of COA in winter (Fig. S35). Overall, COA is an important non-fossil POA sources in all seasons, which should be taken into consideration, especially in autumn.

\section{BBOA}

The BBOA factors that were identified in spring and autumn accounted for 13 and $11 \%$ of OA, respectively. In sum- mer and winter, the contributions of biomass burning to OA might be relatively low (probably $<5 \%$ ) and cannot be resolved in our dataset by PMF. Levoglucosan is a significant tracer of biomass burning emissions, the fragment of which, $\mathrm{C}_{2} \mathrm{H}_{4} \mathrm{O}_{2}^{+}(m / z 60)$ is regarded as a tracer of BBOA (Alfarra et al., 2007; Cubison et al., 2011). The abundance of $m / z 60$ $(\sim 0.8-1.3 \%)$ in the MS of BBOA was much higher than the background abundance $(0.3 \%)$ in the urban without biomass burning emissions, which is a primary feature in identifying BBOA factors. The $\mathrm{O} / \mathrm{C}$ ratios (0.24-0.31) of BBOA factors were higher than those (0.07-0.18) of HOA, and comparable to those (0.2-0.4) in previous studies (Mohr et al., 2009; He et al., 2010, 2011). In spring, farmers start preparing fields and burn straw leftover on the field. In autumn, burning crop straw randomly happens quite often during the harvest season for corn and other crops in North China. These phenomena result in serious atmospheric particulate pollution in Beijing and surrounding areas (Duan et al., 2004; Zheng et al., 2005).

BBOA tracked well (Tables S9 and S11) with chloride, $\mathrm{BC}, \mathrm{C}_{2} \mathrm{H}_{4} \mathrm{O}_{2}^{+}$and acetonitrile, similar to the results of previous studies (DeCarlo et al., 2010; He et al., 2011; Gong et al., 2012). Particles emitted from biomass burning could contain a high proportion of chlorides (Silva et al., 1999). The diurnal variations in BBOA were similar with those of HOA, with higher concentrations at night and in the morning and lower ones in the daytime (see Sect. 3.2.3). They could be partially attributed to similar emission processes, such as residential burning activities.

\section{CCOA}

Coal accounts for two-thirds of the total primary energy consumption and coal combustion is an important source of air pollution in China (You and Xu, 2010; Huang et al., 2014). CCOA was only resolved in winter, consistent with the domestic heating period, suggesting that this CCOA factor was dominated by residential burning with higher OA emission factors (Hu et al., 2016a). Alkyl fragments $\left(\mathrm{C}_{n} \mathrm{H}_{2 n+1}^{+}\right.$and $\mathrm{C}_{n} \mathrm{H}_{2 n-1}^{+}$) are the most abundant in the MS of CCOA. The MS of CCOA also showed pronounced signals of ion fragments from polycyclic aromatic hydrocarbons (PAHs), e.g., $\mathrm{C}_{10} \mathrm{H}_{8}^{+}(m / z 128)$ from naphthalene and $\mathrm{C}_{14} \mathrm{H}_{10}^{+}(m / z 178)$ from anthracene (Fig. S31). The CCOA spectrum in winter is similar to those in our previous studies at Changdao Island and in the winter of Beijing (Hu et al., 2013, 2016a). Compared to the average $\mathrm{H} / \mathrm{C}$ ratios (1.76-1.96) in other POA factors (Canagaratna et al., 2015), $\mathrm{H} / \mathrm{C}$ in CCOA (1.45) is lower. The $\mathrm{O} / \mathrm{C}$ and $\mathrm{OA} / \mathrm{OC}$ ratios in CCOA were 0.14 and 1.32 , respectively. CCOA accounted for $17 \%$ of total OA on average, within the range of 10-33\% reported in other studies in the winter of Beijing (Fig. 5; Hu et al., 2016a). 


\subsubsection{HOA}

HOA is the sum of unresolved reductive and primary OA except specific OA (e.g., COA, BBOA, and CCOA), which is generally considered to be related to the emissions of fossil fuel combustion. The mass spectra (MS) features of HOA in this study are similar to those in previous studies (Huang et al., 2010; Hu et al., 2013; and references therein). Alkyl fragments $\left(\mathrm{C}_{n} \mathrm{H}_{2 n+1}^{+}\right.$and $\left.\mathrm{C}_{n} \mathrm{H}_{2 n-1}^{+}\right)$are abundant in the spectra (Figs. S28-S31). O / C and OA / OC ratios of HOA factors were $0.18,0.19,0.07$, and 0.36 , and $1.40,1.41,1.27$, and 1.63 during four seasons, respectively. Compared with the corresponding ratios $(\mathrm{O} / \mathrm{C}$ : 0.04-0.26; OA / OC: 1.21-1.50) of HOA in previous studies (Canagaratna et al., 2015), the higher values in winter were influenced by the contribution of BBOA. Absolutely independent sources cannot be identified by factor analysis (e.g., PMF model). Therefore, the typical MS features of OA from other primary sources can be found in the MS of HOA. In this study, the abundant fragment ions in the MS of POA factors, e.g., CCOA $(m / z 67$, 69,91 , etc.) and COA $(m / z 55,57$, etc. $)$, were also presented in the MS of HOA (He et al., 2011; Hu et al., 2013, 2016a). This can also be confirmed through the correlations between HOA and external tracers (see Tables S9-S12). HOA tracked well $(r=0.6-0.9, p<0.01)$ with traces of primary emissions (e.g., coal combustion and vehicular exhausts), such as chloride, $\mathrm{NO}_{x}, \mathrm{CO}, \mathrm{BC}$, and $\mathrm{C}_{2} \mathrm{H}_{4} \mathrm{O}_{2}^{+}$, consistent with the primary sources of HOA.

\subsubsection{Oxygenated OA sources}

OOA, considered as a good alternative to SOA in most cases, has been extensively investigated in a large number of previous studies (Jimenez et al., 2009; Zhang et al., 2005; Ulbrich et al., 2009; $\mathrm{Ng}$ et al., 2011). During the seasonal observations, OOA was an important component of OA. In summer and winter, OOA was separated into MO-OOA and LOOOA. Oxygenated fragments $\left(\mathrm{C}_{x} \mathrm{H}_{y} \mathrm{O}_{z}^{+}\right)$are prominent in the MS of OOA. The abundance of $\mathrm{C}_{x} \mathrm{H}_{y} \mathrm{O}_{z}^{+}$in MO-OOA was higher than that in LO-OOA. For instance, the fragment of carboxylic acid $\mathrm{CO}_{2}^{+}(\mathrm{m} / z 44)$ accounted for $17-21 \%$ in MO-OOA, and 7-14\% in LO-OOA. The average O / C ratios for SV-OOA, LV-OOA, and OOA reported in some studies around the world were $0.53,0.84$, and 0.67 , respectively (Canagaratna et al., 2015). In spring and autumn, the O / C ratios of OOA were 1.0 and 0.88 , respectively. In summer and winter, the $\mathrm{O} / \mathrm{C}$ ratios in resolved MO-OOA factors were about 0.91 and 0.84 , higher than those of corresponding LO-OOA (0.67 and 0.77). In all four seasons, O / C ratios of OOA were higher than the average values mentioned above, indicating that OA was much more oxygenated and secondary formation contributed significantly to OA in urban Beijing.

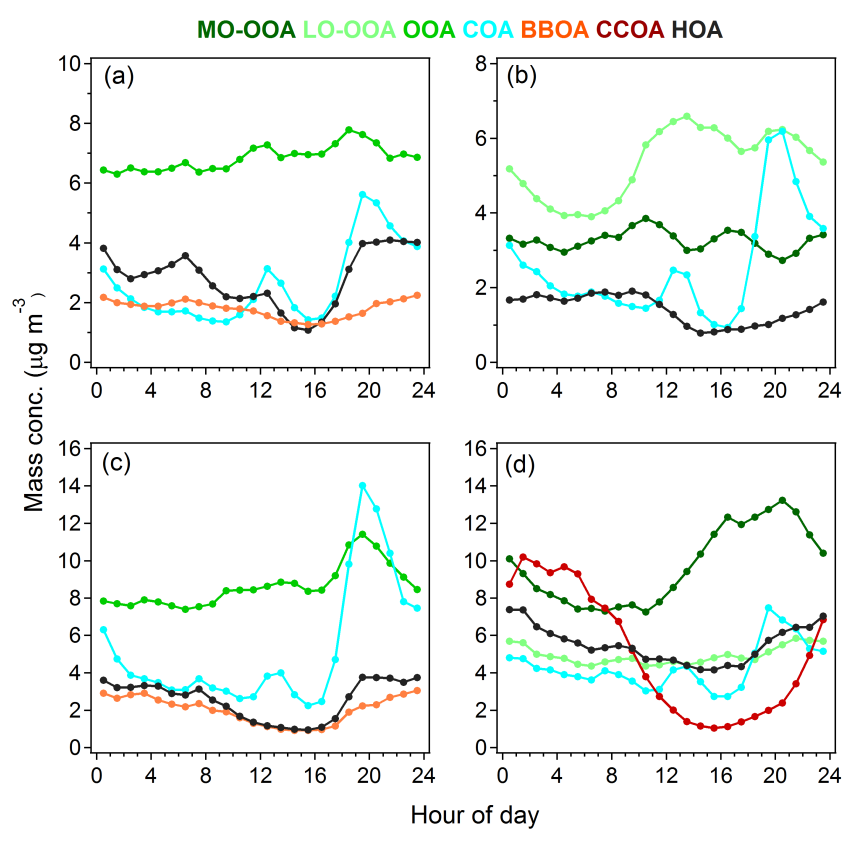

Figure 6. Diurnal variations in OA components in spring (a), summer (b), autumn (c), and winter (d) observations.

Overall, OOA (MO-OOA+LO-OOA) correlated well $(r=$ $0.89-0.96, p<0.01$ ) with secondary inorganics (sulfate and nitrate). MO-OOA, as an extremely aged secondary component, exhibited good correlations with SNA $(r=0.78-0.95$, $p<0.01)$. However, the correlation coefficients $(r=0.63$ $0.89, p<0.01)$ between LO-OOA and SNA were slightly lower (Tables S10 and S12). In summer, LO-OOA and nitrate trended well during most days; during the whole winter campaign, LO-OOA tracked well with nitrate. OOA had strong correlations with RH and/or LWC (Table S14), indicating that aqueous-phase reactions play a dominant role in OOA formation. The slope of OOA against $\mathrm{O}_{x}$ steepened with the increase in RH and LWC (Figs. S41-S42), also implying that the aqueous-phase oxidation was an important pathway of the OOA formation. The good correlations $(r=0.53-0.73, p<0.01)$ between $\mathrm{O}_{x}$ and LO-OOA in summer, and between $\mathrm{O}_{x}$ and OOA in autumn and winter, suggested that photochemical processes also contributed substantially to SOA, especially LO-OOA, in these seasons (Xu et al., 2017). Note that gaseous pollutants and main chemical compositions in $\mathrm{PM}_{1}$ displayed good correlations with each other in winter, which may be caused by regional pollution characteristics under a weak weather system on heavypollution days. 


\subsubsection{Diurnal variations in $\mathrm{OA}$ components}

The diurnal patterns of OA components during seasonal observations are shown in Fig. 6. As mentioned above, the COA factors showed obvious diurnal patterns during all four campaigns, with two peaks around noon (about 13:00) and in the evening (about 20:00), in accordance with living habits of residents. The concentrations of COA factors at the noon peak (about 12:00-14:00) were 3.1, 2.5, 4.0, and $4.4 \mu \mathrm{g} \mathrm{m}^{-3}$ on average, respectively. COA reached the highest concentrations in the evening (18:00-21:00), as 5.6, 6.2, 14.0, and $7.5 \mu \mathrm{g} \mathrm{m}^{-3}$ on average, respectively. HOA was lower in the daytime and higher at night. Nocturnal activities, such as heavy-duty diesel vehicles only permitted at night (Lin et al., 2009), biomass burning and coal combustion, could make more significant contributions to POA. In autumn, the OA concentrations began to raise in the evening, peaked at about 19:00, and kept higher at night (Fig. 2), reaching twice that in the daytime. As Fig. 6c shows, the anthropogenic emissions, e.g., biomass burning, coal combustion, and especially cooking emissions, contributed significantly to OA. In winter, CCOA showed clear diurnal variations with high concentrations at night, consistent with the residential heating periods. The high concentration $\left(10 \mu \mathrm{g} \mathrm{m}^{-3}\right)$ and fraction $(\sim 30 \%)$ of $\mathrm{CCOA}$ in total OA points to strong coal combustion emissions at night in Beijing.

The peaks of OOA (or LO-OOA) coincided with the peaks of primary emitted COA (spring, summer, and autumn) and HOA (winter) in diurnal patterns, probably because strong primary emissions favored SOA production. It has been found that primary emissions evaporate substantially upon dilution to ambient conditions and those vapors undergo photooxidation, which produces SOA efficiently (Robinson et al., 2007; Murphy and Pandis, 2009). Recently, Liu et al. (2017) reported that SOA formed from gas-phase emissions of heated cooking oils. SOA may also be formed after photochemical aging of the large amounts of POA emitted from cooking oils.

In summer, OOA showed obvious diurnal variations: MO-OOA peaked in the morning and afternoon; LO-OOA showed two pronounced peaks at noon and at night. This was likely the co-effect of SOA formation via gas-phase photochemical reactions in the daytime and aqueous chemistry in humid air at night (Ervens et al., 2011; Lim et al., 2010). The concentration and proportion of LO-OOA increased significantly in the afternoon (12:00-16:00), up to $7 \mu \mathrm{g} \mathrm{m}^{-3}$ and $50 \%$, respectively (Fig. 6b), suggesting that LO-OOA was a strong local/regional photochemical product despite the much higher PBL in the daytime (Hu et al., 2016a). Regardless of the air mass history (local, regional, and long-distance transported), LO-OOA dominated OOA, accounting for 29$48 \%$ of OA (Fig. S43). In winter, despite the expanded PBL, MO-OOA increased gradually from noon, and peaked in the evening, implying that MO-OOA could form through photochemical oxidations in the daytime.
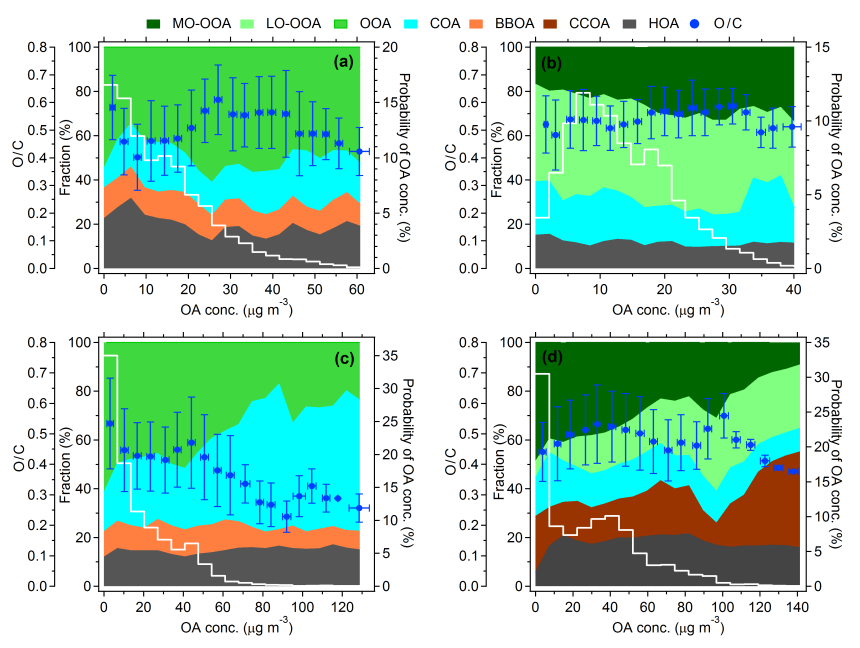

Figure 7. Fractions of OA components at different OA concentration levels and the probability distributions of OA concentrations (white curves) during the spring (a), summer (b), autumn (c), and winter (d) observations. The average $\mathrm{O} / \mathrm{C}$ ratios in each segment are illustrated and the error bars in the $x$ - and $y$-axis were the standard deviations of $\mathrm{OA}$ concentration and $\mathrm{O} / \mathrm{C}$ ratios, respectively.

\subsubsection{Source contributions to the $\mathrm{OA}$ increase}

The probability distributions of $\mathrm{OA}$ and the fractions of OA components as a function of OA concentrations are illustrated in Fig. 7. In spring, autumn and winter, similar to the probability distributions of $\mathrm{PM}_{1}$, the OA concentrations were frequently (about 50-80\%) lower than $10 \mu \mathrm{g} \mathrm{m}^{-3}$, due to the scavenging effect of strong wind accompanying longrange-transported air parcels. In autumn and winter, primary emissions (e.g., cooking emission and coal combustion) influenced strongly, resulting in the wide ranges of OA concentrations, up to 120 and $140 \mu \mathrm{g} \mathrm{m}^{-3}$, respectively. In contrast, OA concentrations presented a skew-normal distribution, mainly in the range of $5-20 \mu \mathrm{g} \mathrm{m}^{-3}$ in summer, similar to previous results (Huang et al., 2010; Hu et al., 2016a).

During the spring observation (Fig. 7a), as the OA concentration was less than $10 \mu \mathrm{g} \mathrm{m}^{-3}$, OOA dominated OA (up to $55 \%$ ), which was likely associated with the new particle formation in clean atmosphere (Wu et al., 2007). When the OA concentration was higher than $10 \mu \mathrm{g} \mathrm{m}^{-3}$, OOA primarily contributed to the increase in OA. The fraction of OOA remained at about 50-60\% as the OA concentration was over $25 \mu \mathrm{g} \mathrm{m}^{-3}$. In summer, as the OA concentration was lower than $30 \mu \mathrm{g} \mathrm{m}^{-3}$, OOA accounted for about $60-70 \%$ of OA (Fig. 7b). As mentioned above, LO-OOA formation was efficient due to both the strong photochemical and aqueousphase processes under high-RH and high-temperature conditions (Xu et al., 2017). With the increase in OA, the fraction of MO-OOA enhanced gradually, implying that the aged MO-OOA contributed importantly to the OA increase. In autumn, with the increase in OA, the proportion of OOA de- 
creased gradually (Fig. 7c). In winter, when the OA concentration was lower than $70 \mu \mathrm{g} \mathrm{m}^{-3}$, OOA and POA contributed equally to OA, while the fraction of LO-OOA increased gradually (Fig. 7d). In both autumn and winter, the fractions of OOA slightly increased around $100 \mu \mathrm{g} \mathrm{m}^{-3}$. More work is needed to accurately clarify the cause of the OOA increase within this range.

In spring, summer, and autumn, as the OA concentration was higher than $30 \mu \mathrm{g} \mathrm{m}^{-3}$, the fraction of COA in OA increased to a different extent, reaching 30-60\%. In autumn, the contributions of BBOA and HOA to OA were relatively stable, while that of COA dramatically enhanced with OA increase, probably because that the static air during some intervals (e.g., 23-25 October) was not conducive to the dispersal of heavy emissions from cooking activities (Figs. S8 and S34). Furthermore, in autumn, considerable barbecue activities in urban Beijing and surrounding areas could be an important source of COA as mentioned above. These results indicate that strong cooking emissions were partially responsible for high OA concentrations in these seasons. In winter, when the OA concentration reached $100 \mu \mathrm{g} \mathrm{m}^{-3}$, the fraction of CCOA dramatically increased, from 10 to about $40 \%$, indicating that the strong emissions from coal combustion contributed predominately to high OA concentrations (Hu et al., 2016a). The O / C ratios of OA at different OA concentrations were dependent on the source contributions, showing lower values when the POA were dominant in all seasons (Fig. 7).

\subsection{The aging process of $\mathrm{OA}$}

\subsubsection{Elemental ratios, van Krevelen diagram, and carbon oxidation state}

Some important metrics or tools, such as elemental ratios, van Krevelen (VK) diagrams, and carbon oxidation state $\left(\mathrm{OS}_{\mathrm{C}}\right)$ of $\mathrm{OA}$, are used to investigate dynamic evolution and oxidation mechanisms for bulk organic aerosols.

The elemental compositions of OA are closely related to their properties, e.g., density, hygroscopicity, and vapor pressure. The element ratios and OA / OC ratios in OA obtained from seasonal observations in Beijing and at other urban and rural/suburban sites are listed in Table 2. During the campaigns, the average $\mathrm{O} / \mathrm{C}$ and $\mathrm{H} / \mathrm{C}$ ratios (in atomic number), and OA / OC ratios were in the range of $0.47-0.53$, $1.52-1.63$, and $1.77-1.88$, respectively. In spring, the average OA / OC ratio in Beijing was lower than those determined in Mexico City and Bologna and at Changdao Island (Table 2). In the summers of 2011-2012, the OA / OC ratios in Beijing were higher than those measured at urban sites in Shenzhen and Riverside, and rural/suburban sites in Jiaxing and Melpitz, indicating a high oxidation state of OA due to strong SOA formation via photochemical reactions in Beijing. However, in summers of 2008 in Beijing and 2010 in Shanghai, the OA / OC ratios were quite lower, maybe because the reduction of pollutant emissions reduced SOA formation during the Beijing Olympic Games and Shanghai World Expo, respectively (Pye et al., 2013). In autumn, the OA / OC ratio in Beijing was slightly higher than that in Shenzhen but far lower than those ratios obtained at rural/suburban sites, e.g., Kaiping, Heshan, and Melpitz. The observed OA / OC ratio in Beijing in winter 2012 was higher than those in Fresno and in Beijing 2010, but comparable to or lower than those at rural/suburban sites such as Ziyang, Jiaxing, and Melpitz. Overall, the OA / OC ratios in Beijing were higher among urban sites except for in spring, and lower among rural/suburban sites except for in summer.

The van Krevelen (VK) diagram is an important tool to investigate the evolution and functional group alteration of $\mathrm{OA}$ (Heald et al., 2010). As shown in Table 3 and Figs. S36-S38, $\mathrm{H} / \mathrm{C}$ and $\mathrm{O} / \mathrm{C}$ ratios of OA exhibit good negative correlation (coefficient of determination $r^{2}=0.70-0.79$ ), with the slopes of $-0.57,-0.62$, and -0.67 and intercepts of 1.91 , 1.94 , and 1.90 in the VK diagram in spring, summer, and autumn, respectively. The slopes are flatter than those $(-0.7$ to -1.0 ) obtained across the world (Chen et al., 2015) but are steeper than that determined in Ziyang (Table 3). The intercepts are slightly lower than those (2.1-2.2) at urban and downwind sites (Chen et al., 2015). However, the VK diagram in winter (Figs. 8 and S39) does not show any correlation $\left(r^{2}=0.02\right)$ between $\mathrm{H} / \mathrm{C}$ and $\mathrm{O} / \mathrm{C}$. The slope is nearly zero $(-0.08)$. This is possibly caused by the more complex sources of OA in winter; for example, CCOA was only resolved in winter.

Heald et al. (2010) concluded that OA trends to evolve along with a slope of -1 in the VK diagram. Ng et al. (2011) derived that the evolution from SV-OOA to LV-OOA is mainly along with a slope of approximately -0.5 , and is associated with the replacement of carboxyl functional group $(\mathrm{OH}-(\mathrm{C}=\mathrm{O})-)$. The identified reactions related to the alteration of functional groups are shown in Fig. 8. In spring, summer, and autumn, the slopes fell between -1 (the addition of carboxyl functional groups without fragmentation or carbonyl and hydroxyl in different carbons) and -0.5 (carboxyl functionalization with fragmentation). In winter, the nearly zero slope of the VK diagram suggests that hydroxylation and/or peroxidation processes (slope $=0$ ) were likely to occur in Beijing during winter. On the other hand, carboxylation process might be unlikely to occur since the slope is higher than -0.5 .

The average carbon oxidation state $\left(\overline{\mathrm{OS}_{\mathrm{C}}}\right)$, approximated by $2 \times \mathrm{O} / \mathrm{C}-\mathrm{H} / \mathrm{C}$, can also reflect the oxidation degree of OA (Kroll et al., 2011). The estimated $\overline{\mathrm{OS}_{\mathrm{C}}}$ values of OA during seasonal observations are listed in Table 2 and the integrated Tri-VK- $\overline{\mathrm{OS}_{\mathrm{C}}}$ diagram is shown as Fig. 8. In summer and winter, the average carbon oxidation states were higher, with an average of $-0.54 \pm 0.27$ (in the range of $-1.42-0.23)$ and $-0.58 \pm 0.25(-1.32-0.11)$, respectively. In spring and autumn, the average carbon oxidation states were $-0.64 \pm 0.37(-1.96-0.55)$ and $-0.66 \pm 0.39(-1.66-$ 
Table 2. Elemental ratios and OA / OC ratios in OA obtained from field observations at urban and rural/suburban sites. The ratios are corrected by the "improved-ambient" method (Canagaratna et al., 2015), except for Hu et al. (2013) and Gong et al. (2013). Abbreviations in parentheses correspond to seasons (sp: spring; su: summer; a: autumn; w: winter).

\begin{tabular}{|c|c|c|c|c|c|c|c|}
\hline Sites & Site types & Periods & $\mathrm{O} / \mathrm{C}$ & $\mathrm{H} / \mathrm{C}$ & $\overline{\mathrm{OS}_{\mathrm{C}}}$ & $\mathrm{OA} / \mathrm{OC}$ & References \\
\hline \multirow[t]{7}{*}{ Beijing (China) } & \multirow[t]{14}{*}{ Urban } & Mar-May 2012 (sp) & 0.49 & 1.63 & -0.64 & 1.81 & This study \\
\hline & & Jul-Aug 2012 (su) & 0.53 & 1.61 & -0.54 & 1.88 & \\
\hline & & Oct-Nov 2012 (a) & 0.46 & 1.58 & -0.66 & 1.77 & \\
\hline & & Jan-Mar 2013 (w) & 0.47 & 1.52 & -0.58 & 1.79 & \\
\hline & & Aug-Sep 2011 (su) & 0.56 & 1.61 & -0.49 & 1.91 & Hu et al. (2016a) \\
\hline & & Nov-Dec 2010 (w) & 0.32 & 1.65 & -1.01 & 1.58 & \\
\hline & & Jul-Sep 2008 (su) & 0.41 & 1.63 & -0.80 & 1.69 & Huang et al. (2010) \\
\hline \multirow[t]{2}{*}{ Shenzhen (China) } & & Oct-Dec 2009 (a) & 0.39 & 1.83 & -1.04 & 1.71 & He et al. (2011) \\
\hline & & Aug-Sep 2011 (su) & $0.45^{*}$ & $1.74^{*}$ & -0.84 & $1.81^{*}$ & Gong et al. (2013) \\
\hline Shanghai (China) & & May-Jun 2010 (su) & 0.40 & 1.92 & -1.12 & 1.69 & Huang et al. (2012) \\
\hline Mexico City (Mexico) & & Mar 2006 (sp) & 0.53 & 1.82 & -0.77 & 1.86 & Aiken et al. (2009) \\
\hline Bologna (Italy) & & Mar-Apr 2008 (sp) & 0.59 & 1.64 & -0.46 & 1.92 & Saarikoski et al. (2012) \\
\hline Fresno, CA (US) & & Jan $2010(w)$ & 0.35 & 1.75 & -1.05 & 1.63 & Ge et al. (2012) \\
\hline Riverside, CA (US) & & Jul-Aug 2005 (su) & 0.44 & 1.71 & -0.82 & 1.73 & Docherty et al. (2011) \\
\hline Kaiping (China) & \multirow[t]{9}{*}{ Rural/suburban } & Oct-Nov 2008 (a) & 0.60 & 1.64 & -0.44 & 1.94 & Huang et al. (2011) \\
\hline Heshan (China) & & Nov-Dec 2010 (a) & 0.50 & 1.63 & -0.63 & 1.87 & Gong et al. (2012) \\
\hline Changdao Island (China) & & Mar-Apr 2011 (sp) & $0.75^{*}$ & $1.48^{*}$ & 0.02 & $2.08^{*}$ & Hu et al. (2013) \\
\hline Ziyang (China) & & Dec 2012-Jan $2013(w)$ & 0.65 & 1.56 & -0.26 & 2.02 & Hu et al. (2016b) \\
\hline \multirow[t]{2}{*}{ Jiaxing (China) } & & Jun-Jul 2010 (su) & 0.36 & 1.94 & -1.22 & 1.67 & Huang et al. (2013) \\
\hline & & Dec $2010(w)$ & 0.43 & 1.73 & -0.87 & 1.75 & \\
\hline \multirow[t]{3}{*}{ Melpitz (Germany) } & & May-Jul 2008 (su) & 0.52 & 1.51 & -0.47 & 1.83 & Poulain et al. (2011) \\
\hline & & Sep-Nov 2008 (a) & 0.54 & 1.48 & -0.40 & 1.84 & \\
\hline & & Feb-Mar 2009 (w) & 0.53 & 1.48 & -0.41 & 1.83 & \\
\hline
\end{tabular}

* The O / C, H / C, and OA / OC ratios were scaled up by 27, 11, and $7 \%$ (the average corrections for ambient OA; Canagaratna et al., 2015), respectively.

0.64). Compared with previous studies, in spring, the $\overline{\mathrm{OS}_{\mathrm{C}}}$ was significantly lower than those at Changdao Island and Bologna sites, but slightly higher than that in Mexico City. In summer, the $\overline{\mathrm{OS}_{\mathrm{C}}}$ was comparable to those in Beijing in 2011 and Melpitz and much higher than those in Beijing in 2008, Shenzhen, Shanghai, Riverside, and Jiaxing. In autumn, it was higher than that in Shenzhen, lower than those in Kaiping and Melpitz, and close to that at Heshan site. The $\overline{\mathrm{OS}_{\mathrm{C}}}$ in winter was significantly higher than those in Beijing 2010, Fresno, and Jiaxing, but lower than those in Ziyang and Melpitz. Compared with the oxidation states of SV-OOA, OOA, and LV-OOA summarized by Canagaratna et al. (2015), the oxidation states of OOA, especially LOOOA, in Beijing were generally higher than in other areas (Fig. 8). The oxidation states of MO-OOA in Beijing were only lower than those in very aged air masses in Ziyang in the basin (Hu et al., 2016b), over Mexico City (DeCarlo et al., 2010) and in Barcelona (Mohr et al., 2012). The oxidation states of LO-OOA were only slightly lower than those of MO-OOA in Beijing and were comparable to those of MOOOA in other urban areas (Fig. 8).

In summary, in urban Beijing, bulk organic aerosols were in a higher oxidation state in summer and in a medium oxidation state in other seasons and were less oxygenated than at several rural/suburban sites. The possible reasons for relatively higher oxidation states of OA in Beijing could be the high hygroscopicity of aerosols and high $\mathrm{OH}$ radical concentration in air (Jimenez et al., 2009). The trend of increasing hygroscopicity with increasing $\mathrm{O} / \mathrm{C}$ is robust based on field observations in Beijing and at several other sites (Jimenez et al., 2009; Wu et al., 2016). Xu et al. (2017) suggest a major role of aqueous-phase processes in increasing the oxidation 
Table 3. Slopes in the van Krevelen diagram based on field observations at urban and background/suburban sites.

\begin{tabular}{|c|c|c|c|c|c|c|c|}
\hline Sites & Site types & Periods & Slope & Intercept & $r^{2}$ & $\mathrm{O} / \mathrm{C}$ range & References \\
\hline \multirow[t]{4}{*}{ Beijing (China) } & \multirow[t]{7}{*}{ Urban } & Mar-May 2012 & -0.57 & 1.91 & 0.74 & $0.12-0.95$ & \multirow[t]{4}{*}{ This study } \\
\hline & & Jul-Aug 2012 & -0.62 & 1.94 & 0.79 & $0.20-0.83$ & \\
\hline & & Oct-Nov 2012 & -0.67 & 1.90 & 0.70 & $0.15-0.92$ & \\
\hline & & Jan-Mar 2013 & -0.08 & 1.56 & 0.02 & $0.18-0.77$ & \\
\hline Mexico City (Mexico) & & Mar 2006 & -0.69 & 2.19 & 0.99 & & Aiken et al. (2009) \\
\hline Fresno (US) & & Jan 2010 & -0.95 & 2.08 & 0.77 & & Ge et al. (2012) \\
\hline Riverside (US) & & Jul-Aug 2005 & -0.96 & 2.13 & 0.81 & & Docherty et al. (2011) \\
\hline Lake Hongze (China) & \multirow[t]{4}{*}{ Background/suburban } & Mar-Apr 2011 & -0.72 & 2.00 & 0.56 & & \multirow[t]{2}{*}{ Zhu et al. (2016) } \\
\hline Mount Wuzhi (China) & & Mar-Apr 2015 & -0.69 & 1.99 & 0.54 & & \\
\hline Ziyang (China) & & Dec 2012-Jan 2013 & -0.44 & 1.84 & 0.70 & $0.12-0.70$ & Hu et al. (2016b) \\
\hline Melpitz (Germany) & & May-Jul 2008 & -0.69 & 1.83 & 0.91 & & Poulain et al. (2011) \\
\hline
\end{tabular}

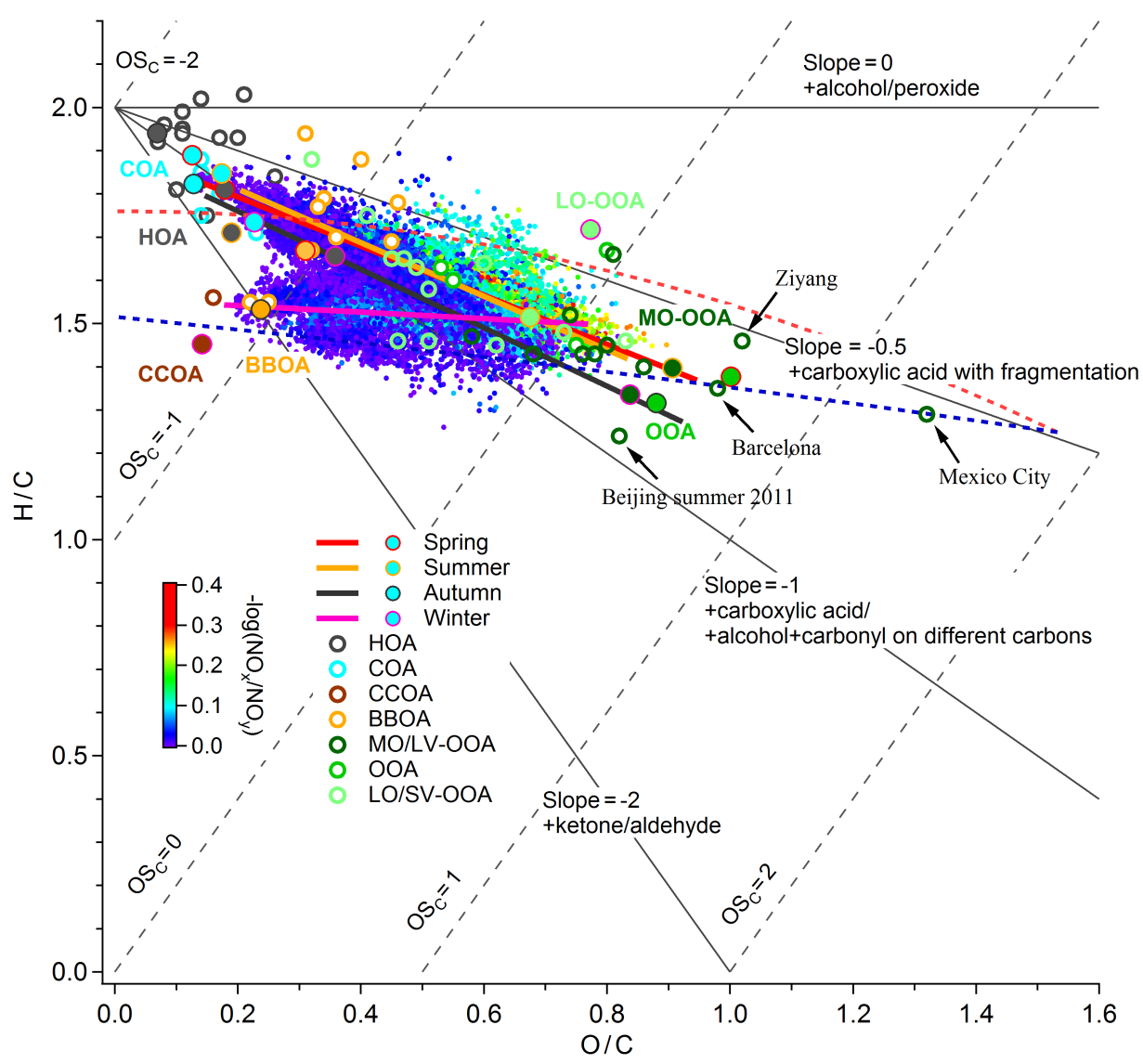

Figure 8. Tri-VK- $\overline{\mathrm{OS}_{\mathrm{C}}}$ diagram based on seasonal observations. The scatterplot of $\mathrm{H} / \mathrm{C}$ vs. $\mathrm{O} / \mathrm{C}$ ratios is colored by the parameter $-\log \left(\mathrm{NO}_{x} / \mathrm{NO}_{y}\right)$. The OA factors resolved by the AMS-PMF analysis are also marked in the diagram. The majority of the data fall within the dashed red and blue lines ( $\mathrm{Ng}$ et al., 2011). Improved-ambient results for OA factors are from Hu et al. (2016a, b) and the summarization of Canagaratna et al. (2015). 

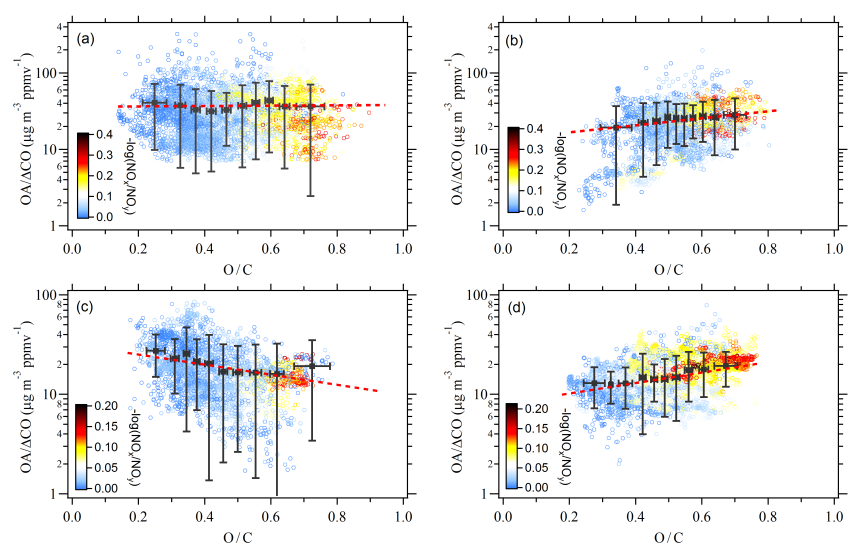

Figure 9. Scatterplots of $\mathrm{OA} / \Delta \mathrm{CO}(\Delta \mathrm{CO}=\mathrm{CO}-0.1)$ ratios vs. $\mathrm{O} / \mathrm{C}$ atomic ratios in $\mathrm{OA}$ during the (a) spring, (b) summer, (c) autumn, and (d) winter observations. The OA / $\triangle \mathrm{CO}$ ratios are in the range of 1st and 99th percentile. The scatterplots are colored by the parameter $-\log \left(\mathrm{NO}_{x} / \mathrm{NO}_{y}\right)$.

degree of SOA in Beijing based on the consistency of higher $\mathrm{O} / \mathrm{C}$ of SOA and higher RH. Lim et al. (2010) suggest that reactions with $\mathrm{OH}$ radicals tend to be faster and form more SOA than non-radical reactions. High daily maximum concentrations $\left(0.4-1.7 \times 10^{7} \mathrm{~cm}^{-3}\right)$ for $\mathrm{OH}$ were observed in the North China Plain (Lu et al., 2013; Tan et al., 2017).

\subsubsection{Evolution of $\mathrm{OA}$ along with the aging of air masses}

The aging process of the air mass indicates that the physical and chemical changes occur and that secondary organics or inorganics form continuously, and the physicochemical properties of the air mass are modified during the transport of the air mass from source areas. In previous studies, the ratio or standardized ratio of $\mathrm{NO}_{x}$ to $\mathrm{NO}_{y}$ concentrations is used as a criterion to characterize the aging degree of air masses (Liang et al., 1998). Here the metric $-\log \left(\mathrm{NO}_{x} / \mathrm{NO}_{y}\right)$ is used to investigate the relationship between OA oxidation and the aging of air masses. The larger the metric is, the more aged the air mass (Kleinman et al., 2008; DeCarlo et al., 2008, 2010).

When $-\log \left(\mathrm{NO}_{x} / \mathrm{NO}_{y}\right)<0.1$, the air plume is considered fresh (Liang et al., 1998). The maxima of the parameter $-\log \left(\mathrm{NO}_{x} / \mathrm{NO}_{y}\right)$ were about $0.4,0.4,0.2$, and 0.2 during seasonal observations. This was consistent with the photochemical reactions being more active in spring and summer due to strong solar radiation, while in autumn and winter the plumes of primary emissions had greater impacts. The urban Beijing was under the control of the relatively aged air masses during some periods (e.g., 23-24 April, 1718 August, and 26-27 October 2012). However, compared with the aerial results in Mexico City, where the highest -log
$\left(\mathrm{NO}_{x} / \mathrm{NO}_{y}\right)$ exceeded 1.4 (DeCarlo et al., 2010), the aging degree of air masses in urban Beijing was much lower.

The scatterplot of $\mathrm{H} / \mathrm{C}$ vs. $\mathrm{O} / \mathrm{C}$ ratios in Tri-VK- $\overline{\mathrm{OS}_{\mathrm{C}}}$ diagram (Fig. 8) is colored with $-\log \left(\mathrm{NO}_{x} / \mathrm{NO}_{y}\right)$. There was a trend that the oxidation state of $\mathrm{OA}$ was higher (i.e., lower $\mathrm{H} / \mathrm{C}$ ratio, and higher $\mathrm{O} / \mathrm{C}$ ratio and $\overline{\mathrm{OS}_{\mathrm{C}}}$ ) as the air mass aged more (from the upper left to the lower right). The OA factors resolved by the AMS-PMF analysis during seasonal campaigns are also marked in Fig. 8. In the order from POA (HOA, COA, CCOA, and BBOA) to SOA (LOOOA, OOA, and MO-OOA), the factors evolved along with the direction to a higher oxidation state, which is consistent with the oxidation characteristics of the factors.

The OA / $\triangle \mathrm{CO}$ ratio is used to evaluate the contribution of SOA formation, where $\triangle \mathrm{CO}$ is $\mathrm{CO}$ subtracted the regional background concentration $(0.1 \mathrm{ppmv})$ to exclude the influences of emitted and transported OA (de Gouw and Jimenez, 2009; DeCarlo et al., 2010). With the SOA formation, the OA $/ \triangle \mathrm{CO}$ ratio increases. The average of OA / $\triangle \mathrm{CO}$ ratios (in the range of 1st and 99th percentile) were $37.0 \pm 30.7,25.0 \pm 16.4,20.3 \pm 16.5$, and $15.1 \pm 8.1 \mathrm{\mu g} \mathrm{m}^{-3} \mathrm{ppmv}^{-1}$, respectively. The ratios were comparable to or higher than the urban $\triangle \mathrm{POA} / \triangle \mathrm{CO}$ ratios $\left(<15 \mu \mathrm{g} \mathrm{m}^{-3} \mathrm{ppmv}^{-1}\right)$, but were much lower than the OA / $\Delta$ CO ratios $\left(70 \pm 20 \mu \mathrm{g} \mathrm{m}^{-3} \mathrm{ppmv}^{-1}\right)$ in aged urban air (de Gouw and Jimenez, 2009), implying that the contribution of POA was considerable in Beijing during seasonal campaigns, especially in autumn and winter.

Investigating the variations in $\mathrm{OA} / \Delta \mathrm{CO}$ ratios with the aging process of air masses can help reveal the formation rate of SOA and parameterize it in the model simulation (Dzepina et al., 2011). The scatterplots of OA / $\Delta \mathrm{CO}$ ratios over O / C ratios during the seasonal observations in Beijing are shown in Fig. 9, colored with the metric $-\log \left(\mathrm{NO}_{x} / \mathrm{NO}_{y}\right)$. In laboratory and field studies on OA aging under strong oxidizing conditions, it was found that the $\mathrm{OA} / \Delta \mathrm{CO}$ ratios remain relatively stable at high $\mathrm{O} / \mathrm{C}$ ratios with the increase in $\mathrm{O} / \mathrm{C}$ ratios because organics obtain oxygen atoms but lose carbon atoms in the oxidation processes (DeCarlo et al., 2008, 2010). During seasonal campaigns in Beijing, the OA / $\Delta C O$ ratios showed different trends with the increase in $\mathrm{O} / \mathrm{C}$ ratios as well as aging degrees of air masses (Fig. 9). Due to the intricate sources of $\mathrm{OA}$ in urban Beijing, the $\mathrm{O} / \mathrm{C}$ ratios cannot reach higher values and the $\mathrm{OA} / \triangle \mathrm{CO}$ cannot remain an obviously stable level. In autumn, the $\mathrm{OA} / \Delta \mathrm{CO}$ ratios decreased with the increase in $\mathrm{O} / \mathrm{C}$ ratios in more aged air masses, suggesting that reductive POA contributed substantially to high OA concentrations. An important reason for the decrease in OA / $\triangle \mathrm{CO}$ ratios in aged air in autumn is the mixing of urban and biomass burning plumes with high CO content (DeCarlo et al., 2010). In summer and winter, along with the increase in $\mathrm{O} / \mathrm{C}$ ratios and the aging degree of air masses, the OA / $\triangle \mathrm{CO}$ ratios trended to increase, indicating the material contribution of SOA formation. Guo et al. (2014) concluded that photochemical oxidations of VOCs 

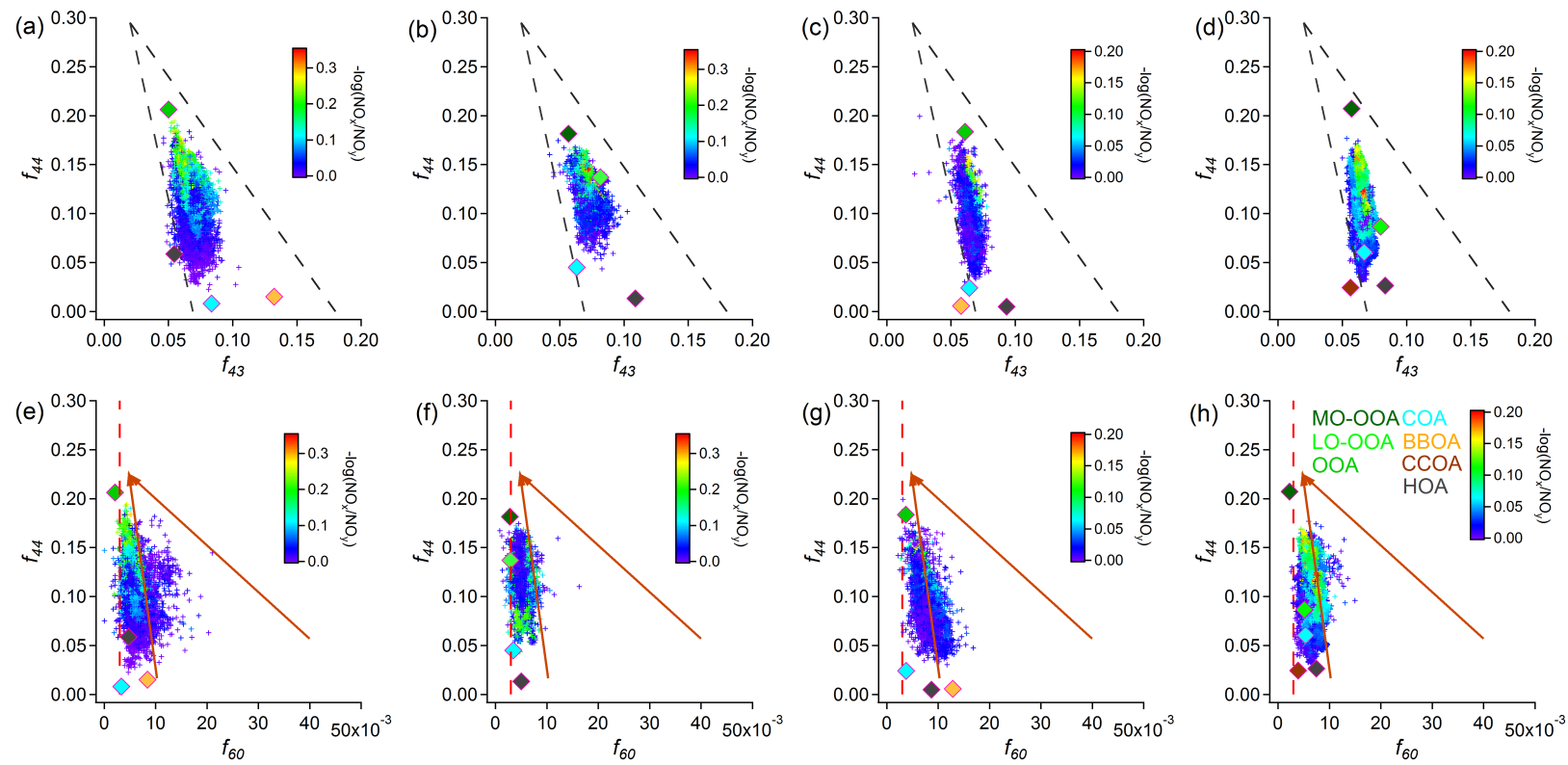

Figure 10. Scatterplots of $f_{44}$ vs. $f_{43}$ and $f_{44}$ vs. $f_{60}$ in OA during the spring (a, e), summer (b, f), autumn (c, g), and winter (d, h) observations. The triangle for $f_{44}$ against $f_{43}$ derived by $\mathrm{Ng}$ et al. (2010) is lineated. The conceptual space for BBOA and the nominal background value at $0.3 \%$ (Cubison et al., 2011) are marked by arrows and vertical dash lines, respectively. The scatterplots are colored by the metric $-\log \left(\mathrm{NO}_{x} / \mathrm{NO}_{y}\right)$. The OA factors resolved by the AMS-PMF analysis are also marked in all diagrams.

from urban traffic emissions are primarily responsible for the secondary formation during severe aerosol pollution events. Many studies have reported the rapid increase in SOA significantly exceeding the initial POA emission ratios in urban atmosphere in a day in the absence of biomass burning (DeCarlo et al., 2010).

In mass spectra measured by AMS, some relatively abundant fragment ions have a certain representativeness. As mentioned above, $m / z 43$ and $m / z 44$, mainly as $\mathrm{C}_{2} \mathrm{H}_{3} \mathrm{O}^{+}$ and $\mathrm{CO}_{2}^{+}$, respectively, are predominant in the MS of OOA. While in the MS of HOA $m / z 43$ is mainly composed of alkyl fragment $\mathrm{C}_{3} \mathrm{H}_{7}^{+}$( $\mathrm{Ng}$ et al., 2010). The difference between the relative contents of $m / z 43$ and $m / z 44$ in OA can reflect the oxidation degree, e.g., the abundance of $m / z 44$ in MO-OOA is higher than that in LO-OOA. The fragment $m / z 60$ (mainly $\mathrm{C}_{2} \mathrm{H}_{4} \mathrm{O}_{2}^{+}$) is often used as a tracer of biomass burning (Alfarra et al., 2007; Cubison et al., 2011).

The scatterplots of $f_{44}$ against $f_{43}$, and $f_{44}$ against $f_{60}$ during seasonal campaigns are shown in Fig. 10, colored with $-\log \left(\mathrm{NO}_{x} / \mathrm{NO}_{y}\right)$. The data points in the scatterplots of $f_{44}$ vs. $f_{43}$ substantially fell into the triangle derived by $\mathrm{Ng}$ et al. (2010). As the aging degree of air masses increased, OA showed the evolution trends moving from the lower right to the upper left generally in the triangle. The POA factors (HOA, COA, CCOA, and BBOA) are concentrated in the bottom of the triangle, LO-OOA with a higher oxidation state is in an intermediate location, and MO-OOA with the highest oxidation state is at the top of the triangle. $\mathrm{Ng}$ et al. (2010) found that with the enhancement of OA oxida- tion, data points gradually move upward from the lower half of the triangle through summarizing the results of chamber experiments and field observations.

In the scatterplots of $f_{44}$ vs. $f_{60}$, the majority of the data points concentrated on the left side and presented in a bandshaped region (Fig. 10e-h). Cubison et al. (2011) found that in the $f_{44}$ against $f_{60}$ space, data from biomass burning appear in the lower right part, while data with negligible biomass burning influence are concentrated on the left side as a band shape. There are a part of data points appearing in the conceptual space for BBOA (Cubison et al., 2011), more obviously in spring, autumn, and winter (Fig. 10e, g, h). In spring and autumn, a large number of data points are of higher $f_{60}$ than in other seasons, and the aging degrees of air masses were low $\left(-\log \left(\mathrm{NO}_{x} / \mathrm{NO}_{y}\right)<0.05\right)$, which may be subject to biomass burning emissions as mentioned above. HOA, COA, CCOA, LO-OOA, MO-OOA, and OOA are located on the left side, while BBOA appears on the right. With the increase in the aging degree of air masses, $f_{60}$ did not trend to change dramatically, suggesting that the contribution of biomass burning to OA has no dependence on the aging degree of air masses.

\section{Conclusions}

We investigated the compositions of submicron aerosols during four seasons in urban Beijing with highly time-resolved 
HR-ToF-AMS measurements. The following conclusions can be drawn:

- The average $\mathrm{PM}_{1}$ was highest $\left(82 \mu \mathrm{g} \mathrm{m}^{-3}\right)$ in winter, resulting from intense emissions due to adverse meteorological conditions and secondary formation, and lowest $\left(38 \mu \mathrm{g} \mathrm{m}^{-3}\right)$ in summer due to frequent washout. Chemical compositions in $\mathrm{PM}_{1}$ also showed seasonal dependence. Carbonaceous fraction $(\mathrm{OA}+\mathrm{BC})$ constituted more than $50 \%$ of $\mathrm{PM}_{1}$ in autumn due to primary emissions, while SNA contributed $60 \%$ of $\mathrm{PM}_{1}$ in other seasons.

- OA was identified as secondary fractions (MO-OOA and LO-OOA, or total OOA) and primary fractions (COA, CCOA, BBOA, and HOA). In summer, OOA dominated OA ( $69 \%)$ due to the crucial contribution of SOA formation, while POA (50-53\% of total OA) was almost equivalent to SOA in other seasons. In winter, SOA contributed to OA much more significantly (50\%) than in previous studies (20-30\%), which may be associated with stronger SOA formation under long-lasting static and heavy-pollution days.

- Secondary species (SNA+SOA) represented about 60$80 \%$ of $\mathrm{PM}_{1}$ in four seasons, stressing the importance of measures targeting the reduction of gaseous precursor $\left(\mathrm{NO}_{x}, \mathrm{SO}_{2}\right.$, and VOCs) emissions.

- OA was in a relatively high oxidation state in urban Beijing according to $\mathrm{OA} / \mathrm{OC}$ and $\mathrm{O} / \mathrm{C}$ ratios as well as $\overline{\mathrm{OS}_{\mathrm{C}}}$, especially in summer and winter. The $\overline{\mathrm{OS}_{\mathrm{C}}}$ values were $-0.64,-0.54,-0.66$, and -0.58 in four seasons, respectively. The evolution of OA was, along with the increase in oxidation state, from POA (HOA, COA, CCOA, and BBOA) to SOA (LO-OOA and MO-OOA). Moreover, higher oxidation states of OA were observed in more aged air masses.

In this study, the chemical compositions of $\mathrm{PM}_{1}$ clearly varied in four seasons. Meteorological conditions and gaseous and particulate emissions determined the severity of atmospheric aerosol pollution. To prevent regional aerosol pollution effectively, further strengthening of the control of primary particulate emissions is expected. In addition, the emissions of secondary species' precursors must be reduced, especially under adverse meteorological conditions.

Data availability. The data presented in this article are available from the authors upon request (minhu@pku.edu.cn).

The Supplement related to this article is available online at https://doi.org/10.5194/acp-17-9979-2017-supplement.
Competing interests. The authors declare that they have no conflict of interest.

Acknowledgements. This work was supported by the National Natural Science Foundation of China (91544214, 41421064, 51636003), the National Basic Research Program of China (2013CB228503), and the National Key Research and Development Program of China (2016YFC0202003). The authors express their appreciation to Min Shao and Yudong Yang in Peking University for data of VOCs and Jeffrey Morrow in the Prefectural University of Kumamoto for his assistance in language editing.

Edited by: Jason Surratt

Reviewed by: three anonymous referees

\section{References}

Aiken, A. C., Salcedo, D., Cubison, M. J., Huffman, J. A., DeCarlo, P. F., Ulbrich, I. M., Docherty, K. S., Sueper, D., Kimmel, J. R., Worsnop, D. R., Trimborn, A., Northway, M., Stone, E. A., Schauer, J. J., Volkamer, R. M., Fortner, E., de Foy, B., Wang, J., Laskin, A., Shutthanandan, V., Zheng, J., Zhang, R., Gaffney, J., Marley, N. A., Paredes-Miranda, G., Arnott, W. P., Molina, L. T., Sosa, G., and Jimenez, J. L.: Mexico City aerosol analysis during MILAGRO using high resolution aerosol mass spectrometry at the urban supersite (T0) - Part 1: Fine particle composition and organic source apportionment, Atmos. Chem. Phys., 9, 6633-6653, https://doi.org/10.5194/acp-9-6633-2009, 2009.

Alfarra, M. R., Prevot, A. S., Szidat, S., Sandradewi, J., Weimer, S., Lanz, V. A., Schreiber, D., Mohr, M., and Baltensperger, U.: Identification of the mass spectral signature of organic aerosols from wood burning emissions, Environ. Sci. Technol. 41, 57705777, 2007.

Allan, J. D., Williams, P. I., Morgan, W. T., Martin, C. L., Flynn, M. J., Lee, J., Nemitz, E., Phillips, G. J., Gallagher, M. W., and Coe, H.: Contributions from transport, solid fuel burning and cooking to primary organic aerosols in two UK cities, Atmos. Chem. Phys., 10, 647-668, https://doi.org/10.5194/acp-10-6472010, 2010.

Bond, T. C., Doherty, S. J., Fahey, D. W., Forster, P. M., Berntsen, T., DeAngelo, B. J., Flanner, M. G., Ghan, S., Kärcher, B., Koch, D., Kinne, S., Kondo, Y., Quinn, P. K., Sarofim, M. C., Schultz, M. G., Schulz, M., Venkataraman, C., Zhang, H., Zhang, S., Bellouin, N., Guttikunda, S. K., Hopke, P. K., Jacobson, M. Z., Kaiser, J. W., Klimont, Z., Lohmann, U., Schwarz, J. P., Shindell, D., Storelvmo, T., Warren, S. G., and Zender, C. S.: Bounding the role of black carbon in the climate system: A scientific assessment, J. Geophys. Res.-Atmos., 118, 5380-5552, https://doi.org/10.1002/jgrd.50171, 2013.

Budisulistiorini, S. H., Baumann, K., Edgerton, E. S., Bairai, S. T., Mueller, S., Shaw, S. L., Knipping, E. M., Gold, A., and Surratt, J. D.: Seasonal characterization of submicron aerosol chemical composition and organic aerosol sources in the southeastern United States: Atlanta, Georgia,and Look Rock, Tennessee, Atmos. Chem. Phys., 16, 5171-5189, https://doi.org/10.5194/acp16-5171-2016, 2016. 
Buseck, P. R. and Adachi, K.: Nanoparticles in the Atmosphere, Elements, 4, 389-394, https://doi.org/10.2113/gselements.4.6.389, 2008.

Canagaratna, M. R., Jimenez, J. L., Kroll, J. H., Chen, Q., Kessler, S. H., Massoli, P., Hildebrandt Ruiz, L., Fortner, E., Williams, L. R., Wilson, K. R., Surratt, J. D., Donahue, N. M., Jayne, J. T., and Worsnop, D. R.: Elemental ratio measurements of organic compounds using aerosol mass spectrometry: characterization, improved calibration, and implications, Atmos. Chem. Phys., 15, 253-272, https://doi.org/10.5194/acp-15-253-2015, 2015.

Carlton, A. G., Wiedinmyer, C., and Kroll, J. H.: A review of Secondary Organic Aerosol (SOA) formation from isoprene, Atmos. Chem. Phys., 9, 4987-5005, https://doi.org/10.5194/acp-9-49872009, 2009.

Chen, Q., Heald, C. L., Jimenez, J. L., Canagaratna, M. R., Zhang, Q., He, L.-Y., Huang, X.-F., Campuzano-Jost, P., Palm, B. B., Poulain, L., Kuwata, M., Martin, S. T., Abbatt, J. P. D., Lee, A. K. Y., and Liggio, J.: Elemental composition of organic aerosol: The gap between ambient and laboratory measurements, Geophys. Res. Lett., 42, 4182-4189, https://doi.org/10.1002/2015gl063693, 2015.

Cubison, M. J., Ortega, A. M., Hayes, P. L., Farmer, D. K., Day, D., Lechner, M. J., Brune, W. H., Apel, E., Diskin, G. S., Fisher, J. A., Fuelberg, H. E., Hecobian, A., Knapp, D. J., Mikoviny, T., Riemer, D., Sachse, G. W., Sessions, W., Weber, R. J., Weinheimer, A. J., Wisthaler, A., and Jimenez, J. L.: Effects of aging on organic aerosol from open biomass burning smoke in aircraft and laboratory studies, Atmos. Chem. Phys., 11, 12049-12064, https://doi.org/10.5194/acp-11-12049-2011, 2011.

Dall'Osto, M., Paglione, M., Decesari, S., Facchini, M. C., O'Dowd, C., Plass-Duellmer, C., and Harrison, R. M.: On the origin of AMS "Cooking Organic Aerosol" at a rural site, Environ. Sci. Technol., 49, 13964-13972, 2015.

DeCarlo, P. F., Dunlea, E. J., Kimmel, J. R., Aiken, A. C., Sueper, D., Crounse, J., Wennberg, P. O., Emmons, L., Shinozuka, Y., Clarke, A., Zhou, J., Tomlinson, J., Collins, D. R., Knapp, D., Weinheimer, A. J., Montzka, D. D., Campos, T., and Jimenez, J. L.: Fast airborne aerosol size and chemistry measurements above Mexico City and Central Mexico during the MILAGRO campaign, Atmos. Chem. Phys., 8, 4027-4048, https://doi.org/10.5194/acp-8-4027-2008, 2008.

DeCarlo, P. F., Ulbrich, I. M., Crounse, J., de Foy, B., Dunlea, E. J., Aiken, A. C., Knapp, D., Weinheimer, A. J., Campos, T., Wennberg, P. O., and Jimenez, J. L.: Investigation of the sources and processing of organic aerosol over the Central Mexican Plateau from aircraft measurements during MILAGRO, Atmos. Chem. Phys., 10, 5257-5280, https://doi.org/10.5194/acp10-5257-2010, 2010.

de Gouw, J. and Jimenez, J. L.: Organic aerosols in the Earth's atmosphere, Environ. Sci. Technol., 43, 7614-7618, 2009.

Docherty, K. S., Aiken, A. C., Huffman, J. A., Ulbrich, I. M., DeCarlo, P. F., Sueper, D., Worsnop, D. R., Snyder, D. C., Peltier, R. E., Weber, R. J., Grover, B. D., Eatough, D. J., Williams, B. J., Goldstein, A. H., Ziemann, P. J., and Jimenez, J. L.: The 2005 Study of Organic Aerosols at Riverside (SOAR-1): instrumental intercomparisons and fine particle composition, Atmos. Chem. Phys., 11, 12387-12420, https://doi.org/10.5194/acp-11-123872011, 2011.
Duan, F., Liu, X., Yu, T., and Cachier, H.: Identification and estimate of biomass burning contribution to the urban aerosol organic carbon concentrations in Beijing, Atmos. Environ., 38, 1275-1282, 2004.

Dyer, J. M., Stymne, S., Green, A. G., and Carlsson, A. S.: High-value oils from plants, Plant J., 54, 640-655, https://doi.org/10.1111/j.1365-313X.2008.03430.x, 2008.

Dzepina, K., Cappa, C. D., Volkamer, R. M., Madronich, S., DeCarlo, P. F., Zaveri, R. A., and Jimenez, J. L.: Modeling the multiday evolution and aging of secondary organic aerosol during MILAGRO 2006, Environ. Sci. Technol., 45, 3496-3503, 2011.

Ervens, B., Turpin, B. J., and Weber, R. J.: Secondary organic aerosol formation in cloud droplets and aqueous particles (aqSOA): a review of laboratory, field and model studies, Atmos. Chem. Phys., 11, 11069-11102, https://doi.org/10.5194/acp-1111069-2011, 2011.

Fabian, P., Kohlpaintner, M., and Rollenbeck, R.: Biomass burning in the Amazon-fertilizer for the mountaineous rain forest in Ecuador, Environ. Sci. Pollut. R., 12, 290-296, 2005.

Ge, X. L., Setyan, A., Sun, Y. L., and Zhang, Q.: Primary and secondary organic aerosols in Fresno, California during wintertime: Results from high resolution aerosol mass spectrometry, J. Geophys. Res.-Atmos., 117, D19301, https://doi.org/10.1029/2012jd018026, 2012.

Gong, Z., Lan, Z., Xue, L., Zeng, L., He, L., and Huang, X.: Characterization of submicron aerosols in the urban outflow of the central Pearl River Delta region of China, Front. Environ. Sci. Eng., 6, 725-733, 2012.

Gong, Z., Xue, L., Sun, T., Deng, Y., He, L., and Huang, X.: Online measurement of $\mathrm{PM}_{1}$ chemical composition and size distribution using a high-resolution aerosol mass spectrometer during 2011 Shenzhen Universiade, Sci. Sinica Chim., 43, 363-372, https://doi.org/10.1360/032012-384, 2013.

Guo, S., Hu, M., Wang, Z. B., Slanina, J., and Zhao, Y. L.: Sizeresolved aerosol water-soluble ionic compositions in the summer of Beijing: implication of regional secondary formation, Atmos. Chem. Phys., 10, 947-959, https://doi.org/10.5194/acp-10-9472010, 2010.

Guo, S., Hu, M., Guo, Q., Zhang, X., Zheng, M., Zheng, J., Chang, C. C., Schauer, J. J., and Zhang, R.: Primary sources and secondary formation of organic aerosols in Beijing, China, Environ. Sci. Technol., 46, 9846-9853, 2012.

Guo, S., Hu, M., Guo, Q., Zhang, X., Schauer, J. J., and Zhang, R.: Quantitative evaluation of emission controls on primary and secondary organic aerosol sources during Beijing 2008 Olympics, Atmos. Chem. Phys., 13, 8303-8314, https://doi.org/10.5194/acp-13-8303-2013, 2013.

Guo, S., Hu, M., Zamora, M. L., Peng, J., Shang, D., Zheng, J., Du, Z., Wu, Z., Shao, M., Zeng, L., Molina, M. J., and Zhang, R.: Elucidating severe urban haze formation in China, P. Natl. Acad. Sci. USA, 111, 17373-17378, 2014.

Hallquist, M., Wenger, J. C., Baltensperger, U., Rudich, Y., Simpson, D., Claeys, M., Dommen, J., Donahue, N. M., George, C., Goldstein, A. H., Hamilton, J. F., Herrmann, H., Hoffmann, T., Iinuma, Y., Jang, M., Jenkin, M. E., Jimenez, J. L., Kiendler-Scharr, A., Maenhaut, W., McFiggans, G., Mentel, Th. F., Monod, A., Prévôt, A. S. H., Seinfeld, J. H., Surratt, J. D., Szmigielski, R., and Wildt, J.: The formation, properties and impact of secondary organic aerosol: current and emerging issues, 
Atmos. Chem. Phys., 9, 5155-5236, https://doi.org/10.5194/acp9-5155-2009, 2009.

He, L.-Y., Lin, Y., Huang, X.-F., Guo, S., Xue, L., Su, Q., Hu, M., Luan, S.-J., and Zhang, Y.-H.: Characterization of highresolution aerosol mass spectra of primary organic aerosol emissions from Chinese cooking and biomass burning, Atmos. Chem. Phys., 10, 11535-11543, https://doi.org/10.5194/acp-10-115352010, 2010.

He, L. Y., Huang, X. F., Xue, L., Hu, M., Lin, Y., Zheng, J., Zhang, R., and Zhang, Y.-H.: Submicron aerosol analysis and organic source apportionment in an urban atmosphere in Pearl River Delta of China using high-resolution aerosol mass spectrometry, J. Geophys. Res.-Atmos., 116, D12304, https://doi.org/10.1029/2010JD014566, 2011.

Heald, C. L., Kroll, J. H., Jimenez, J. L., Docherty, K. S., DeCarlo, P. F., Aiken, A. C., Chen, Q., Martin, S. T., Farmer, D. K., and Artaxo, P.: A simplified description of the evolution of organic aerosol composition in the atmosphere, Geophys. Res. Lett., 37, L08803, https://doi.org/10.1029/2010gl042737, 2010.

Hu, W., Hu, M., Hu, W., Jimenez, J. L., Yuan, B., Chen, W., Wang, M., Wu, Y., Chen, C., Wang, Z., Peng, J., Zeng, L., and Shao, M.: Chemical composition, sources and aging process of sub-micron aerosols in Beijing: contrast between summer and winter, J. Geophys. Res.-Atmos., 121, 1955-1977, https://doi.org/10.1002/2015JD024020, 2016a.

Hu, W., Hu, M., Hu, W.-W., Niu, H., Zheng, J., Wu, Y., Chen, W., Chen, C., Li, L., Shao, M., Xie, S., and Zhang, Y.: Characterization of submicron aerosols influenced by biomass burning at a site in the Sichuan Basin, southwestern China, Atmos. Chem. Phys., 16, 13213-13230, https://doi.org/10.5194/acp-16-132132016, 2016 b.

Hu, W. W., Hu, M., Deng, Z. Q., Xiao, R., Kondo, Y., Takegawa, N., Zhao, Y. J., Guo, S., and Zhang, Y. H.: The characteristics and origins of carbonaceous aerosol at a rural site of PRD in summer of 2006, Atmos. Chem. Phys., 12, 1811-1822, https://doi.org/10.5194/acp-12-1811-2012, 2012.

Hu, W. W., Hu, M., Yuan, B., Jimenez, J. L., Tang, Q., Peng, J. F., Hu, W., Shao, M., Wang, M., Zeng, L. M., Wu, Y. S., Gong, Z. H., Huang, X. F., and He, L. Y.: Insights on organic aerosol aging and the influence of coal combustion at a regional receptor site of central eastern China, Atmos. Chem. Phys., 13, 10095-10112, https://doi.org/10.5194/acp-13-10095-2013, 2013.

Hu, W. W., Campuzano-Jost, P., Palm, B. B., Day, D. A., Ortega, A. M., Hayes, P. L., Krechmer, J. E., Chen, Q., Kuwata, M., Liu, Y. J., de Sá, S. S., McKinney, K., Martin, S. T., Hu, M., Budisulistiorini, S. H., Riva, M., Surratt, J. D., St. Clair, J. M., Isaacman-Van Wertz, G., Yee, L. D., Goldstein, A. H., Carbone, S., Brito, J., Artaxo, P., de Gouw, J. A., Koss, A., Wisthaler, A., Mikoviny, T., Karl, T., Kaser, L., Jud, W., Hansel, A., Docherty, K. S., Alexander, M. L., Robinson, N. H., Coe, H., Allan, J. D., Canagaratna, M. R., Paulot, F., and Jimenez, J. L.: Characterization of a real-time tracer for isoprene epoxydiols-derived secondary organic aerosol (IEPOX-SOA) from aerosol mass spectrometer measurements, Atmos. Chem. Phys., 15, 11807-11833, https://doi.org/10.5194/acp-15-11807-2015, 2015.

Huang, R. J., Zhang, Y., Bozzetti, C., Ho, K. F., Cao, J. J., Han, Y., Daellenbach, K. R., Slowik, J. G., Platt, S. M., Canonaco, F., Zotter, P., Wolf, R., Pieber, S. M., Bruns, E. A., Crippa, M., Ciarelli, G., Piazzalunga, A., Schwikowski, M., Abbaszade, G., Schnelle-
Kreis, J., Zimmermann, R., An, Z., Szidat, S., Baltensperger, U., El Haddad, I., and Prevot, A. S.: High secondary aerosol contribution to particulate pollution during haze events in China, Nature, 514, 218-222, 2014.

Huang, X.-F., He, L.-Y., Hu, M., Canagaratna, M. R., Sun, Y., Zhang, Q., Zhu, T., Xue, L., Zeng, L.-W., Liu, X.-G., Zhang, Y.-H., Jayne, J. T., Ng, N. L., and Worsnop, D. R.: Highly time-resolved chemical characterization of atmospheric submicron particles during 2008 Beijing Olympic Games using an Aerodyne High-Resolution Aerosol Mass Spectrometer, Atmos. Chem. Phys., 10, 8933-8945, https://doi.org/10.5194/acp-108933-2010, 2010.

Huang, X.-F., He, L.-Y., Hu, M., Canagaratna, M. R., Kroll, J. H., Ng, N. L., Zhang, Y.-H., Lin, Y., Xue, L., Sun, T.L., Liu, X.-G., Shao, M., Jayne, J. T., and Worsnop, D. R.: Characterization of submicron aerosols at a rural site in Pearl River Delta of China using an Aerodyne High-Resolution Aerosol Mass Spectrometer, Atmos. Chem. Phys., 11, 18651877, https://doi.org/10.5194/acp-11-1865-2011, 2011.

Huang, X.-F., He, L.-Y., Xue, L., Sun, T.-L., Zeng, L.-W., Gong, Z.-H., Hu, M., and Zhu, T.: Highly time-resolved chemical characterization of atmospheric fine particles during 2010 Shanghai World Expo, Atmos. Chem. Phys., 12, 4897-4907, https://doi.org/10.5194/acp-12-4897-2012, 2012.

Huang, X. F., Xue, L., Tian, X. D., Shao, W. W., Sun, T. L., Gong, Z. H., Ju, W. W., Jiang, B., Hu, M., and He, L.-Y.: Highly timeresolved carbonaceous aerosol characterization in Yangtze River Delta of China: Composition, mixing state and secondary formation, Atmos. Environ., 64, 200-207, 2013.

Jimenez, J. L., Canagaratna, M. R., Donahue, N. M., Prevot, A. S. H., Zhang, Q., Kroll, J. H., DeCarlo, P. F., Allan, J. D., Coe, H., Ng, N. L., Aiken, A. C., Docherty, K. S., Ulbrich, I. M., Grieshop, A. P., Robinson, A. L., Duplissy, J., Smith, J. D., Wilson, K. R., Lanz, V. A., Hueglin, C., Sun, Y. L., Tian, J., Laaksonen, A., Raatikainen, T., Rautiainen, J., Vaattovaara, P., Ehn, M., Kulmala, M., Tomlinson, J. M., Collins, D. R., Cubison, M. J., Dunlea, J., Huffman, J. A., Onasch, T. B., Alfarra, M. R., Williams, P. I., Bower, K., Kondo, Y., Schneider, J., Drewnick, F., Borrmann, S., Weimer, S., Demerjian, K., Salcedo, D., Cottrell, L., Griffin, R., Takami, A., Miyoshi, T., Hatakeyama, S., Shimono, A., Sun, J. Y., Zhang, Y. M., Dzepina, K., Kimmel, J. R., Sueper, D., Jayne, J. T., Herndon, S. C., Trimborn, A. M., Williams, L. R., Wood, E. C., Middlebrook, A. M., Kolb, C. E., Baltensperger, U., and Worsnop, D. R.: Evolution of organic aerosols in the atmosphere, Science, 326, 1525-1529, https://doi.org/10.1126/science.1180353, 2009.

Kleinman, L. I., Springston, S. R., Daum, P. H., Lee, Y.-N., Nunnermacker, L. J., Senum, G. I., Wang, J., Weinstein-Lloyd, J., Alexander, M. L., Hubbe, J., Ortega, J., Canagaratna, M. R., and Jayne, J.: The time evolution of aerosol composition over the Mexico City plateau, Atmos. Chem. Phys., 8, 1559-1575, https://doi.org/10.5194/acp-8-1559-2008, 2008.

Kroll, J. H., Donahue, N. M., Jimenez, J. L., Kessler, S. H., Canagaratna, M. R., Wilson, K. R., Altieri, K. E., Mazzoleni, L. R., Wozniak, A. S., Bluhm, H., Mysak, E. R., Smith, J. D., Kolb, C. E., and Worsnop, D. R.: Carbon oxidation state as a metric for describing the chemistry of atmospheric organic aerosol, Nat. Chem., 3, 133-139, 2011. 
Lanz, V. A., Alfarra, M. R., Baltensperger, U., Buchmann, B., Hueglin, C., Szidat, S., Wehrli, M. N., Wacker, L., Weimer, S., Caseiro, A., Puxbaum, H., and Prevot, A. S. H.: Source attribution of submicron organic aerosols during wintertime inversions by advanced factor analysis of aerosol mass spectra, Environ. Sci. Technol., 42, 214-220, 2008.

Lee, A. K.: Haze formation in China: Importance of secondary aerosol, J. Environ. Sci., 33, 261-262, 2015.

Lee, S.-H. and Allen, H. C.: Analytical measurements of atmospheric urban aerosol, Anal. Chem., 84, 1196-1201, 2012.

Li, Y. J., Lee, B. P., Su, L., Fung, J. C. H., and Chan, C. K.: Seasonal characteristics of fine particulate matter (PM) based on highresolution time-of-flight aerosol mass spectrometric (HR-ToFAMS) measurements at the HKUST Supersite in Hong Kong, Atmos. Chem. Phys., 15, 37-53, https://doi.org/10.5194/acp-1537-2015, 2015.

Liang, J., Horowitz, L. W., Jacob, D. J., Wang, Y., Fiore, A. M., Logan, J. A., Gardner, G. M., and Munger, J. W.: Seasonal budgets of reactive nitrogen species and ozone over the United States, and export fluxes to the global atmosphere, J. Geophys. Res.-Atmos., 103, 13435-13450, https://doi.org/10.1029/97JD03126, 1998.

Lim, Y. B., Tan, Y., Perri, M. J., Seitzinger, S. P., and Turpin, B. J.: Aqueous chemistry and its role in secondary organic aerosol (SOA) formation, Atmos. Chem. Phys., 10, 1052110539, https://doi.org/10.5194/acp-10-10521-2010, 2010.

Lin, P., Hu, M., Deng, Z., Slanina, J., Han, S., Kondo, Y., Takegawa, N., Miyazaki, Y., Zhao, Y., and Sugimoto, N.: Seasonal and diurnal variations of organic carbon in $\mathrm{PM}_{2.5}$ in Beijing and the estimation of secondary organic carbon, J. Geophys. Res.-Atmos., 114, D00G11, https://doi.org/10.1029/2008JD010902, 2009.

Liu, T., Li, Z., Chan, M., and Chan, C. K.: Formation of secondary organic aerosols from gas-phase emissions of heated cooking oils, Atmos. Chem. Phys., 17, 7333-7344, https://doi.org/10.5194/acp-17-7333-2017, 2017.

Lu, K. D., Hofzumahaus, A., Holland, F., Bohn, B., Brauers, T., Fuchs, H., Hu, M., Häseler, R., Kita, K., Kondo, Y., Li, X., Lou, S. R., Oebel, A., Shao, M., Zeng, L. M., Wahner, A., Zhu, T., Zhang, Y. H., and Rohrer, F.: Missing $\mathrm{OH}$ source in a suburban environment near Beijing: observed and modelled $\mathrm{OH}$ and $\mathrm{HO}_{2}$ concentrations in summer 2006, Atmos. Chem. Phys., 13, 10571080, https://doi.org/10.5194/acp-13-1057-2013, 2013.

Middlebrook, A. M., Bahreini, R., Jimenez, J. L., and Canagaratna, M. R.: Evaluation of Composition-Dependent Collection efficiencies for the Aerodyne aerosol mass spectrometer using field data, Aerosol Sci. Technol., 46, 258-271, 2012.

Mohr, C., Huffman, J. A., Cubison, M. J., Aiken, A. C., Docherty, K. S., Kimmel, J. R., Ulbrich, I. M., Hannigan, M., and Jimenez, J. L.: Characterization of primary organic aerosol emissions from meat cooking, trash burning, and motor vehicles with highresolution aerosol mass spectrometry and comparison with ambient and chamber observations, Environ. Sci. Technol., 43, $2443-$ 2449, 2009.

Mohr, C., DeCarlo, P. F., Heringa, M. F., Chirico, R., Slowik, J. G., Richter, R., Reche, C., Alastuey, A., Querol, X., Seco, R., Peñuelas, J., Jiménez, J. L., Crippa, M., Zimmermann, R., Baltensperger, U., and Prévôt, A. S. H.: Identification and quantification of organic aerosol from cooking and other sources in Barcelona using aerosol mass spectrometer data, Atmos.
Chem. Phys., 12, 1649-1665, https://doi.org/10.5194/acp-121649-2012, 2012.

Murphy, B. N. and Pandis, S. N.: Simulating the formation of semivolatile primary and secondary organic aerosol in a regional chemical transport model, Environ. Sci. Technol., 43, 47224728, 2009.

Ndiaye, P. M., Tavares, F. W., Dalmolin, I., Dariva, C., Oliveira, D., and Oliveira, J. V.: Vapor pressure data of soybean oil, castor oil, and their fatty acid ethyl ester derivatives, J. Chem. Eng. Data, 50, 330-333, https://doi.org/10.1021/je049898o, 2005.

Ng, N. L., Canagaratna, M. R., Zhang, Q., Jimenez, J. L., Tian, J., Ulbrich, I. M., Kroll, J. H., Docherty, K. S., Chhabra, P. S., Bahreini, R., Murphy, S. M., Seinfeld, J. H., Hildebrandt, L., Donahue, N. M., DeCarlo, P. F., Lanz, V. A., Prévôt, A. S. H., Dinar, E., Rudich, Y., and Worsnop, D. R.: Organic aerosol components observed in Northern Hemispheric datasets from Aerosol Mass Spectrometry, Atmos. Chem. Phys., 10, 46254641, https://doi.org/10.5194/acp-10-4625-2010, 2010.

Ng, N. L., Canagaratna, M. R., Jimenez, J. L., Chhabra, P. S., Seinfeld, J. H., and Worsnop, D. R.: Changes in organic aerosol composition with aging inferred from aerosol mass spectra, Atmos. Chem. Phys., 11, 6465-6474, https://doi.org/10.5194/acp11-6465-2011, 2011.

Pieber, S. M., El Haddad, I., Slowik, J. G., Canagaratna, M. R., Jayne, J. T., Platt, S. M., Bozzetti, C., Daellenbach, K. R., Frohlich, R., Vlachou, A., Klein, F., Dommen, J., Miljevic, B., Jimenez, J. L., Worsnop, D. R., Baltensperger, U., and Prevot, A. S.: Inorganic salt interference on $\mathrm{CO}_{2}^{+}$in Aerodyne AMS and ACSM organic aerosol composition studies, Environ. Sci. Technol., 50, 10494-10503, 2016.

Poulain, L., Spindler, G., Birmili, W., Plass-Dülmer, C., Wiedensohler, A., and Herrmann, H.: Seasonal and diurnal variations of particulate nitrate and organic matter at the IfT research station Melpitz, Atmos. Chem. Phys., 11, 12579-12599, https://doi.org/10.5194/acp-11-12579-2011, 2011.

Pye, H. O., Pinder, R. W., Piletic, I. R., Xie, Y., Capps, S. L., Lin, Y.-H., Surratt, J. D., Zhang, Z., Gold, A., and Luecken, D. J.: Epoxide pathways improve model predictions of isoprene markers and reveal key role of acidity in aerosol formation, Environ. Sci. Technol., 47, 11056-11064, 2013.

Robinson, A. L., Donahue, N. M., Shrivastava, M. K., Weitkamp, E. A., Sage, A. M., Grieshop, A. P., Lane, T. E., Pierce, J. R., and Pandis, S. N.: Rethinking organic aerosols: Semivolatile emissions and photochemical aging, Science, 315, 1259-1262, 2007.

Saarikoski, S., Carbone, S., Decesari, S., Giulianelli, L., Angelini, F., Canagaratna, M., Ng, N. L., Trimborn, A., Facchini, M. C., Fuzzi, S., Hillamo, R., and Worsnop, D.: Chemical characterization of springtime submicrometer aerosol in Po Valley, Italy, Atmos. Chem. Phys., 12, 8401-8421, https://doi.org/10.5194/acp12-8401-2012, 2012.

Setyan, A., Zhang, Q., Merkel, M., Knighton, W. B., Sun, Y., Song, C., Shilling, J. E., Onasch, T. B., Herndon, S. C., Worsnop, D. R., Fast, J. D., Zaveri, R. A., Berg, L. K., Wiedensohler, A., Flowers, B. A., Dubey, M. K., and Subramanian, R.: Characterization of submicron particles influenced by mixed biogenic and anthropogenic emissions using high-resolution aerosol mass spectrometry: results from CARES, Atmos. Chem. Phys., 12, 8131-8156, https://doi.org/10.5194/acp-12-8131-2012, 2012. 
Silva, P. J., Liu, D.-Y., Noble, C. A., and Prather, K. A.: Size and chemical characterization of individual particles resulting from biomass burning of local Southern California species, Environ. Sci. Technol., 33, 3068-3076, 1999.

Sun, J., Zhang, Q., Canagaratna, M. R., Zhang, Y., Ng, N. L., Sun, Y., Jayne, J. T., Zhang, X., Zhang, X., and Worsnop, D. R.: Highly time- and size-resolved characterization of submicron aerosol particles in Beijing using an Aerodyne Aerosol Mass Spectrometer, Atmos. Environ., 44, 131-140, 2010.

Sun, Y., Wang, Z., Dong, H., Yang, T., Li, J., Pan, X., Chen, P., and Jayne, J. T.: Characterization of summer organic and inorganic aerosols in Beijing, China with an Aerosol Chemical Speciation Monitor, Atmos. Environ., 51, 250-259, 2012.

Sun, Y., Wang, Z., Fu, P., Jiang, Q., Yang, T., Li, J., and Ge, X.: The impact of relative humidity on aerosol composition and evolution processes during wintertime in Beijing, China, Atmos. Environ., 77, 927-934, 2013.

Sun, Y., Jiang, Q., Wang, Z., Fu, P., Li, J., Yang, T., and Yin, Y.: Investigation of the sources and evolution processes of severe haze pollution in Beijing in January 2013, J. Geophys. Res.-Atmos., 119, 4380-4398, 2014.

Sun, Y. L., Wang, Z. F., Fu, P. Q., Yang, T., Jiang, Q., Dong, H. B., Li, J., and Jia, J. J.: Aerosol composition, sources and processes during wintertime in Beijing, China, Atmos. Chem. Phys., 13, 4577-4592, https://doi.org/10.5194/acp-13-4577-2013, 2013.

Sun, Y. L., Wang, Z. F., Du, W., Zhang, Q., Wang, Q. Q., Fu, P. Q., Pan, X. L., Li, J., Jayne, J., and Worsnop, D. R.: Longterm real-time measurements of aerosol particle composition in Beijing, China: seasonal variations, meteorological effects, and source analysis, Atmos. Chem. Phys., 15, 10149-10165, https://doi.org/10.5194/acp-15-10149-2015, 2015.

Tan, Z., Fuchs, H., Lu, K., Hofzumahaus, A., Bohn, B., Broch, S., Dong, H., Gomm, S., Häseler, R., He, L., Holland, F., Li, X., Liu, Y., Lu, S., Rohrer, F., Shao, M., Wang, B., Wang, M., Wu, Y., Zeng, L., Zhang, Y., Wahner, A., and Zhang, Y.: Radical chemistry at a rural site (Wangdu) in the North China Plain: observation and model calculations of $\mathrm{OH}, \mathrm{HO}_{2}$ and $\mathrm{RO}_{2}$ radicals, Atmos. Chem. Phys., 17, 663-690, https://doi.org/10.5194/acp17-663-2017, 2017.

Turpin, B. J., Saxena, P., and Andrews, E.: Measuring and simulating particulate organics in the atmosphere: problems and prospects, Atmos. Environ., 34, 2983-3013, 2000.

Ulbrich, I. M., Canagaratna, M. R., Zhang, Q., Worsnop, D. R., and Jimenez, J. L.: Interpretation of organic components from Positive Matrix Factorization of aerosol mass spectrometric data, Atmos. Chem. Phys., 9, 2891-2918, https://doi.org/10.5194/acp-92891-2009, 2009.

Wang, Q., Shao, M., Zhang, Y., Wei, Y., Hu, M., and Guo, S.: Source apportionment of fine organic aerosols in Beijing, Atmos. Chem. Phys., 9, 8573-8585, https://doi.org/10.5194/acp-9-8573-2009, 2009.

Weimer, S., Drewnick, F., Hogrefe, O., Schwab, J. J., Rhoads, K., Orsini, D., Canagaratna, M., Worsnop, D. R., and Demerjian, K. L.: Size-selective nonrefractory ambient aerosol measurements during the Particulate Matter Technology Assessment and Characterization Study-New York 2004 Winter Intensive in New York City, J. Geophys. Res.-Atmos., 111, D18305, https://doi.org/10.1029/2006JD007215, 2006.
Wu, Z. J., Hu, M., Liu, S., Wehner, B., Bauer, S., Ssling, A. M., Wiedensohler, A., Petaja, T., Dal Maso, M., and Kulmala, M.: New particle formation in Beijing, China: Statistical analysis of a 1-year data set, J. Geophys. Res.-Atmos., 112, D09209, https://doi.org/10.1029/2006JD007406, 2007.

Wu, Z. J., Cheng, Y. F., Hu, M., Wehner, B., Sugimoto, N., and Wiedensohler, A.: Dust events in Beijing, China (20042006): comparison of ground-based measurements with columnar integrated observations, Atmos. Chem. Phys., 9, 6915-6932, https://doi.org/10.5194/acp-9-6915-2009, 2009.

Wu, Z. J., Zheng, J., Shang, D. J., Du, Z. F., Wu, Y. S., Zeng, L. M., Wiedensohler, A., and Hu, M.: Particle hygroscopicity and its link to chemical composition in the urban atmosphere of Beijing, China, during summertime, Atmos. Chem. Phys., 16, 1123 1138, https://doi.org/10.5194/acp-16-1123-2016, 2016.

Xu, J., Zhang, Q., Chen, M., Ge, X., Ren, J., and Qin, D.: Chemical composition, sources, and processes of urban aerosols during summertime in northwest China: insights from high-resolution aerosol mass spectrometry, Atmos. Chem. Phys., 14, 1259312611, https://doi.org/10.5194/acp-14-12593-2014, 2014.

Xu, W., Han, T., Du, W., Wang, Q., Chen, C., Zhao, J., Zhang, Y., Li, J., Fu, P., Wang, Z., Worsnop, D. R., and Sun, Y.: Effects of aqueous-phase and photochemical processing on secondary organic aerosol formation and evolution in Beijing, China, Environ. Sci. Technol., 51, 762-770, 2017.

You, C. and $\mathrm{Xu}, \mathrm{X}$.: Coal combustion and its pollution control in China, Energy, 35, 4467-4472, 2010.

Zhang, J. K., Sun, Y., Liu, Z. R., Ji, D. S., Hu, B., Liu, Q., and Wang, Y. S.: Characterization of submicron aerosols during a month of serious pollution in Beijing, 2013, Atmos. Chem. Phys., 14, 2887-2903, https://doi.org/10.5194/acp-14-2887-2014, 2014.

Zhang, Q., Alfarra, M. R., Worsnop, D. R., Allan, J. D., Coe, H., Canagaratna, M. R., and Jimenez, J. L.: Deconvolution and quantification of hydrocarbon-like and oxygenated organic aerosols based on aerosol mass spectrometry, Environ. Sci. Technol., 39, 4938-4952, 2005.

Zhang, Q., Jimenez, J. L., Canagaratna, M. R., Ulbrich, I. M., Ng, N. L., Worsnop, D. R., and Sun, Y.: Understanding atmospheric organic aerosols via factor analysis of aerosol mass spectrometry: a review, Anal. Bioanal. Chem., 401, 3045-3067, 2011.

Zhang, Y., Sun, J., Zhang, X., Shen, X., Wang, T., and Qin, M.: Seasonal characterization of components and size distributions for submicron aerosols in Beijing, Sci. China Earth Sci., 56, 890900, 2013.

Zhang, Y. M., Zhang, X. Y., Sun, J. Y., Hu, G. Y., Shen, X. J., Wang, Y. Q., Wang, T. T., Wang, D. Z., and Zhao, Y.: Chemical composition and mass size distribution of $\mathrm{PM}_{1}$ at an elevated site in central east China, Atmos. Chem. Phys., 14, 12237-12249, https://doi.org/10.5194/acp-14-12237-2014, 2014.

Zheng, X., Liu, X., Zhao, F., Duan, F., Yu, T., and Cachier, H.: Seasonal characteristics of biomass burning contribution to Beijing aerosol, Sci. China Ser. B Chem., 48, 481-488, 2005.

Zhu, Q., He, L.-Y., Huang, X.-F., Cao, L.-M., Gong, Z.-H., Wang, C., Zhuang, X., and Hu, M.: Atmospheric aerosol compositions and sources at two national background sites in northern and southern China, Atmos. Chem. Phys., 16, 10283-10297, https://doi.org/10.5194/acp-16-10283-2016, 2016. 